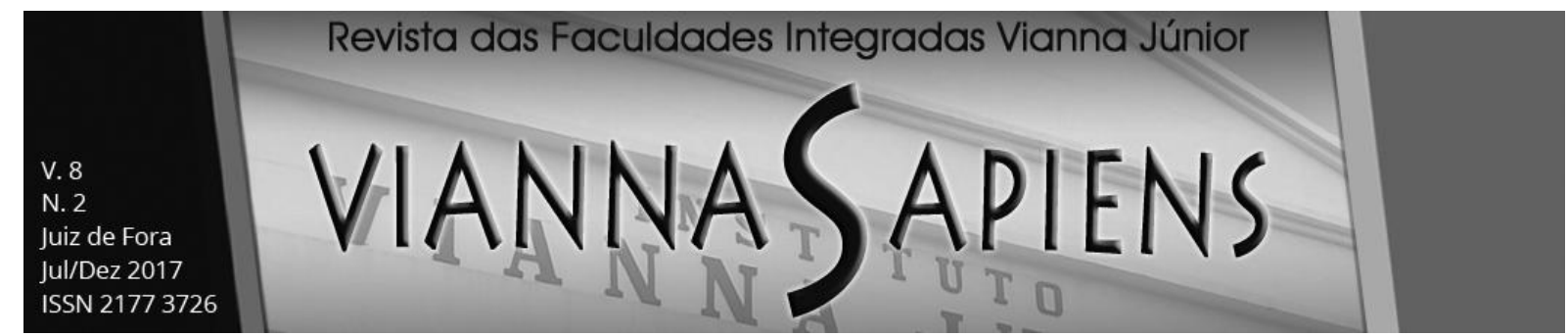

\title{
DIREITO AO DESENVOLVIMENTO NOS ÂMBITOS DO DESENVOLVIMENTO DA NAÇÃO E DO DESENVOLVIMENTO DO INDIVÍDUO
}

\author{
Amanda Garcia de Oliveira ${ }^{1}$ \\ Gustavo Rocha Martins ${ }^{2}$
}

\section{RESUMO}

O direito ao desenvolvimento englobaria a aplicação de todos os direitos para o livre desenvolvimento da sua personalidade, portanto o presente trabalho teria como objetivo analisar as duas dimensões do direito ao desenvolvimento, o desenvolvimento do indivíduo e o desenvolvimento da nação, como também a aplicação e as inovações desse direito. Essa pesquisa será teórica, bibliográfica e documental. No âmbito do desenvolvimento da nação, esse direito está atrelado ao desenvolvimento econômico, ao social e a outros, ou seja, abrange o progresso humano, com todas suas variáveis. Ainda no desenvolvimento da nação, o objeto desse estudo ainda trabalha o desenvolvimento igualitário. Em relação ao desenvolvimento do indivíduo, esse consistiria no pleno gozo dos direitos para que cada pessoa tenha como progredir. As principais conclusões do trabalho foram a discrepância no desenvolvimento humano entre regiões geograficamente próximas, a mudança no sentido da expressão "direito ao desenvolvimento", que, anteriormente, estava atrelado somente ao desenvolvimento econômico, e a necessidade de indicadores do desenvolvimento humano mais precisos.

\footnotetext{
1 Acadêmica do curso de Direito das Faculdades Integradas Vianna Júnior, e-mail: amandagoliveira27@gmail.com.

${ }^{2}$ Mestre em "Hermenêutica" pela Universidade Presidente Antônio Carlos (UNIPAC) e professor das Faculdades Integradas Vianna Júnior, e-mail: gmartins@vianna.edu.br
} 


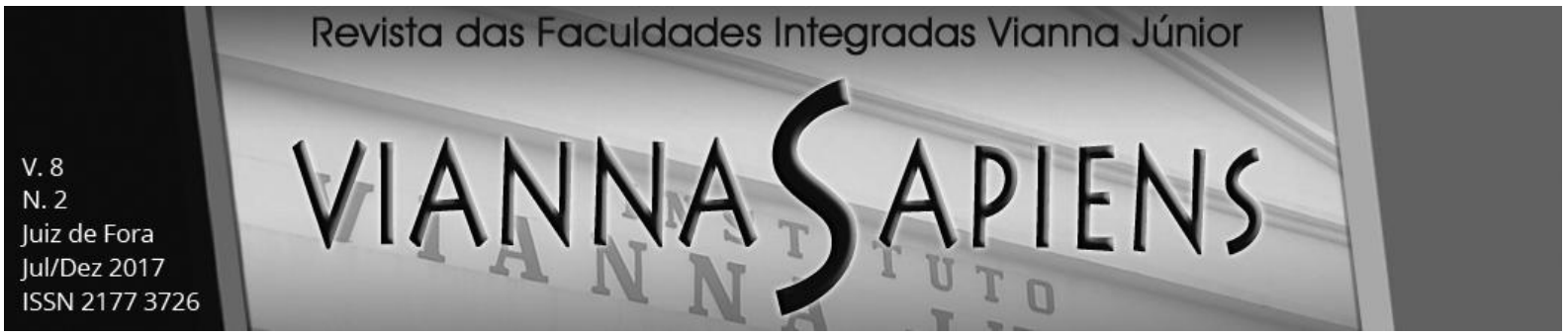

\section{PALAVRAS-CHAVE: DIREITO AO DESENVOLVIMENTO. NAÇÃO. INDIVÍDUO. IDH. DIREITOS HUMANOS.}

\section{INTRODUÇÃO}

Noberto Bobbio, no livro "A era dos direitos" (2004), defende que a proteção dos direitos dos homens está baseada em dois fatores: a democracia e a paz. Aproteção desses direitos tem por base as Constituições democráticas, como a Constituição brasileira de 1988, em que o Estado concede aos cidadãos alguns direitos. Também, a paz seria um pressuposto necessário na efetivação deles, visto que, em momentos de guerra, diversos direitos são suprimidos e violados. Sem essas duas condições, um Estado democrático de direito e a paz, não é possível a efetivação dos direitos do homem (BOBBIO, 2004).

O referido autor defende uma evolução dos direitos, que passaram de direitos das "gentes" para direitos dos "cidadãos' de um Estado ou do mundo, essa mudança é um resultado de fenômenos sociais, que geraram a multiplicação deles. Tal avanço é percebido à proporção que os bens tutelados aumentaram, os titulares foram ampliados e o ser humano, na sua singularidade, foi considerado para a formulação desses direitos (BOBBIO, 2004). Decorrente dessa multiplicação, está o direito ao desenvolvimento, que é uma proteção que engloba a efetivação de todos os bens conservados pelos direitos dos homens e visa ao progresso de todos os indivíduos, sem distinção e com todas suas individualidades.

Esse direito só pode ser efetivado durante tempos de paz e por meio de um Estado democrático, como Noberto Bobbio (2004) sustenta, os dois fatores imprescindíveis para a proteção dos direitos, caso contrário, em tempos de guerra, o homem não pode progredir da maneira que deveria, e, sem democracia, não há um sujeito passivo para proteger os direitos dos indivíduos. Bobbio (2004), do mesmo modo, discute sobre a dificuldade de realização desses direitos, pois, frequentemente, a efetivação dos direitos depende de múltiplos agentes e existe, 


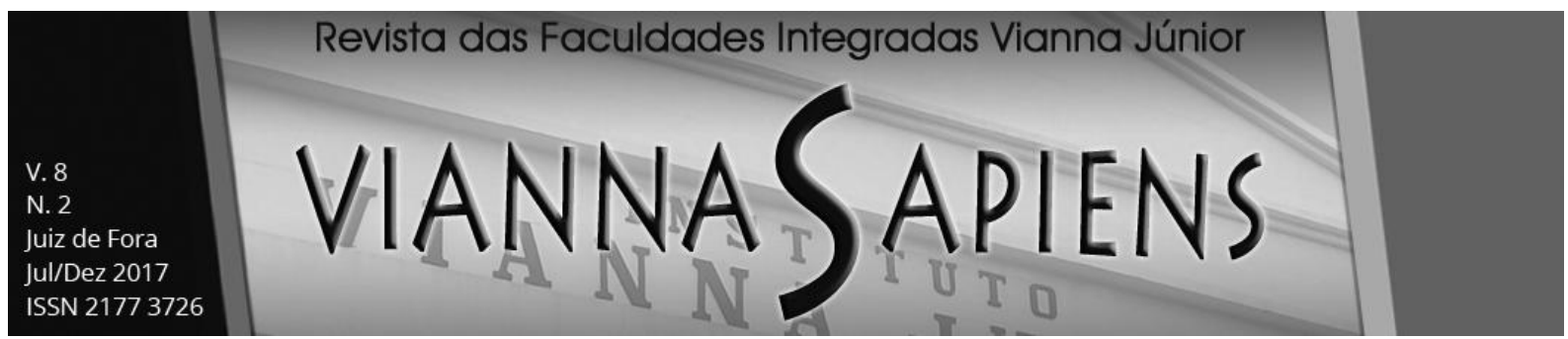

ininterruptamente, uma necessidade de aperfeiçoamento, atualização e especificação desses direitos por meio da comunidade internacional.

No caso do direito ao desenvolvimento, ao longo dos séculos, os meios primordiais para o progresso do indivíduo foram se alterando, como, por exemplo, atualmente, a pessoa precisa de um conhecimento e de aparelhos tecnológicos para conseguir uma vaga de emprego, que, antigamente, seria preenchida pela pessoa com maiores atributos físicos.

Dessa maneira, considerando a importância do direito ao desenvolvimento, o artigo tentará responder a seguinte questão-problema: o que são as duas dimensões do direito ao desenvolvimento, o desenvolvimento do indivíduo e o desenvolvimento da nação e como eles são aplicados nos países?

O presente trabalho tem como objetivo: analisar as duas dimensões do direito ao desenvolvimento - o desenvolvimento do indivíduo e o desenvolvimento da nação - como também a aplicação e as inovações desse direito. Para atingir esse fim, o artigo trará, em sua primeira parte, os conceitos dos direitos fundamentais, e sua evolução, do direito ao desenvolvimento e seus dois âmbitos, como também, denominações relacionadas a esse direito. Em um segundo momento, o trabalho correlacionará o segundo âmbito do direito ao desenvolvimento, o desenvolvimento da nação, com suas interferências no Estado e na sociedade. Na terceira parte do estudo, será analisada a aplicação do direito ao desenvolvimento do indivíduo e como essa faceta é tratada pela doutrina. Na última parte do artigo, serão demonstradas as doutrinas mais atuais sobre o direito ao desenvolvimento e exemplificada a aplicação do direito ao desenvolvimento, por meio de normas, projetos e políticas governamentais, em alguns países, como o Brasil.

O desenvolvimento do trabalho será realizado de forma pura no que se refere à natureza, pois a pesquisa será teórica. Nesse sentido, é uma pesquisa bibliográfica e documental por meio do fichamento de autores que discorrem sobre o tema abordado nesse trabalho. Múltiplos autores do campo do direito e da economia, por exemplo, serão utilizados no desenvolvimento do artigo científico e na conclusão do estudo. 


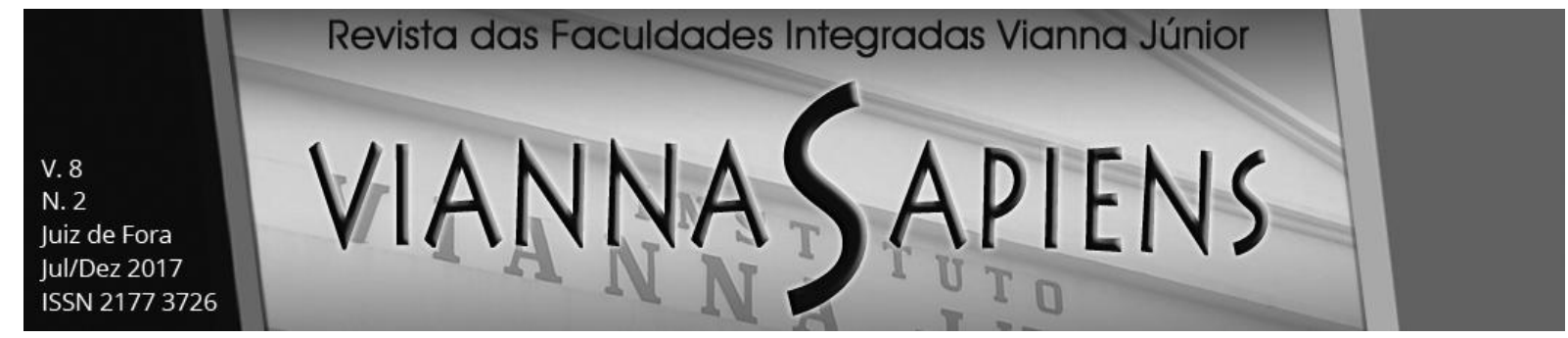

Como apresentado, o estudo do direito ao desenvolvimento é de suma relevância, pois esse direito está atrelado a diversos direitos humanos, como o direito a saúde, educação, vida, dentre outros. Sendo assim, o direito ao desenvolvimento é uma das bases para a aplicação e a proteçãodos direitos humanos, como, também, é a finalidade que todos esses direitos querem atingir, ou seja, os direitos humanos, quando aplicados, promovem uma educação de qualidade, uma alimentação boa e todos os amparos básicos para a pessoa desenvolver-se e progredir.

Esse direito deve ser profundamente estudado para auxiliar governos a desenvolver políticas públicas para fortalecer e crescer - seja economicamente, seja socialmente, ou em qualquer outro setor da sociedade - a sua nação. Além do mais, o direito ao desenvolvimento prevê que todos os segmentos da sociedade progridam juntos, reduzindo a desigualdade social existente em diversos países. Assim sendo, o tema é um auxílio para um crescimento igualitário das nações e envolve inúmeras campos de estudo, como economia e diferentes áreas do direito, principalmente o direito constitucional.

\section{CONCEITOS INICIAIS}

Os direitos do homem transformaram-se, no decorrer da história, de acordo com as necessidades da população ou de grupos específicos, os cenários político e social do mundo ou de uma nação, dentre outros fatores, isto posto, "os direitos humanos são fruto de um espaço simbólico de luta e ação social, na busca por dignidade humana" (p. 194, PIOVESAN, 2016). Dessa forma, os direitos foram divididos em gerações, ou dimensões, que não se excluem, mas acrescentam e alteram direitos estabelecidos anteriormente. A primeira geração foi estabelecida pela Revolução Francesa e pela Revolução Americana, sendo documentadas, respectivamente, pela "Declaração Francesa dos Direitos do Homem" e pela "Constituição dos Estados Unidos da América de 1787" (COMPARATO, 2015). Essa 


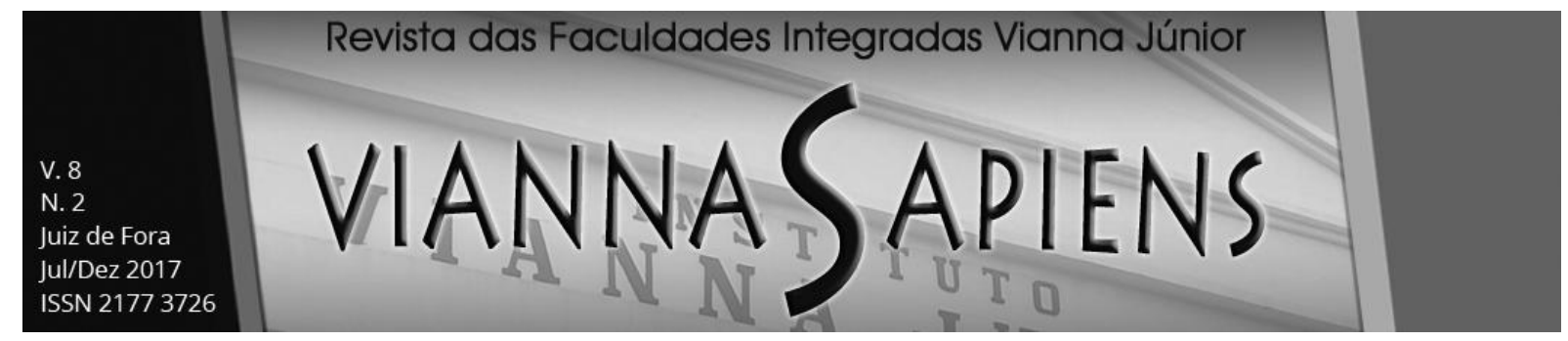

geração estabeleceu a igualdade, a liberdade e a fraternidade dentre os homens, lema da Revolução Francesa.

A segunda geração dos direitos humanos estabeleceu as proteções econômicas e sociais da classe trabalhadora, visto que esse grupo vivia em uma condição miserável, de pobreza, doença, marginalização e fome, perante os patrões que exploravam os mais pobres (COMPARATO, 2015). Na metade do século XIX, a terceira geração de direito é estabelecida, baseando-se no "direito humanitário, na luta contra a escravidão e na regulação dos direitos do trabalhador assalariado" (p. 67, COMPARATO, 2015), um dos documentos emblemáticos é a "Convenção de Genebra", como, também, foi ratificada a "Declaração Universal dos Direitos Humanos" das Nações Unidas.

Alguns autores discutem a existência de uma quarta geração de direitos humanos, seriam os direitos da solidariedade, como, por exemplo, o direito à democracia, à informação e ao pluralismo, bem como a projeção de uma quinta geração de direitos, que envolveria as dimensões anteriores e seria a geração da esperança (MAZZUOLI, 2016). Dessa maneira, segundo Fábio Konder Comparato (p. 42, 2015), "a essência do ser humano é evolutiva, porque a personalidade de cada indivíduo, isto é, o seu ser próprio, é sempre, na duração de sua vida, algo de incompleto e inacabado, uma realidade em contínua transformação", assim, os direitos humanos sempre irão se transformar e evoluir, de acordo com as necessidades humanas da época.

Existe uma diferença, atualmente, dentre direitos fundamentais e direitos humanos. Os direitos fundamentais são aqueles protegidos internamente pelo Estado e que advém de legislações internas, como o título II da Constituição da República Federativa do Brasil de 1988, "Dos Direitos e Garantias Fundamentais". Ademais, eles não são, necessariamente, protegidos por outros Estados, pois cada país tem sua autonomia e, consequentemente, os direitos e os deveres protegidos (MAZZUOLI, 2016).

Em relação aos direitos humanos, são aqueles protegidos pela ordem internacional e são ratificados pelos Estados que celebram tratados, convenções e 


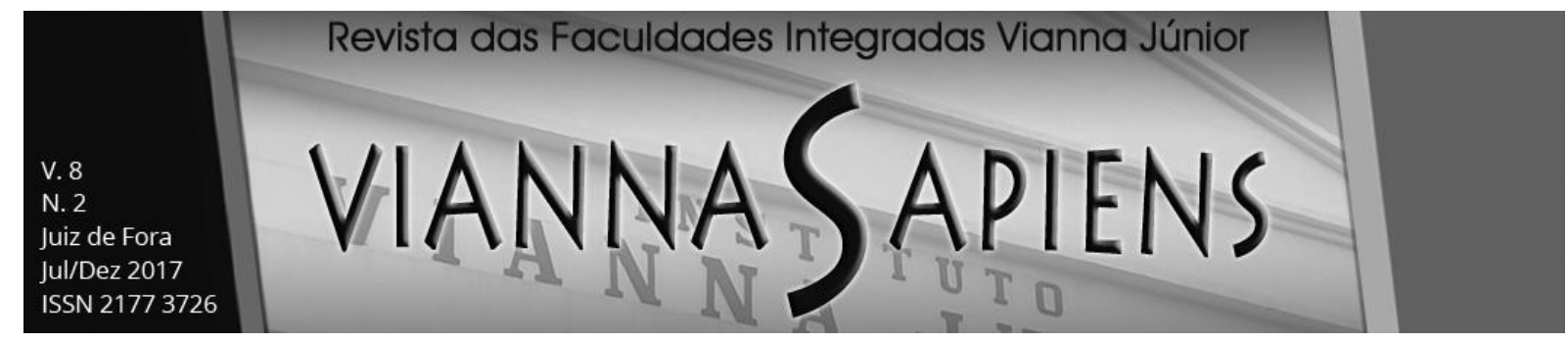

declarações internacionais, como a Declaração Universal de Direitos Humanos (1948). Dessa forma, são "direitos indispensáveis a uma vida digna e que, por isso, estabelecem um nível protetivo (standard) mínimo que todos os Estados devem respeitar, sob pena de responsabilidade internacional" (p. 22, MAZZUOLI, 2016), por isso, todos os Estados signatários têm que proteger e estimular esses direitos, estabelecendo, assim, o sistema internacional de proteção aos direitos humanos.

Um desses direitos humanos é o direito ao desenvolvimento, que estáprevisto na Declaração Universal de Direitos Humanos (ORGANIZAÇÃO DAS NAÇÕES UNIDAS, 1948) em três artigos 22, 26 e 29. O artigo 26 reconhece o direito à instrução, ou à educação, que deve ser gratuita e obrigatória (instrução elementar), como, também, a educação técnico-profissional e a superior deverão ser acessíveis a todos. Esse direito tem como finalidades o "pleno desenvolvimento da personalidade humana" e o"fortalecimento do respeito pelos direitos humanos e pelas liberdades fundamentais" (ORGANIZAÇÃO DAS NAÇÕES UNIDAS, 1948).

Já o artigo 29, ele legitima que todo ser humano tem direitos e liberdades, que devem ser exercidos nos limites da lei para que não transgridam os direitos de outrem. Além disso, os deveres de todo ser humano para com a comunidade devem possibilitar "o livre e pleno desenvolvimento de sua personalidade". Portanto, para o desenvolvimento da personalidade do ser humano,são necessárias a proteção e a aplicação de seus direitos humanos, tal como o direito à educação, e o indivíduo tem que exercer seus deveres proporcionando seu desenvolvimento (ORGANIZAÇÃO DAS NAÇÕES UNIDAS, 1948). Esse direito está compreendido no artigo 22, o qual consagra que

todo ser humano, como membro da sociedade, tem direito à segurança social e à realização, pelo esforço nacional, pela cooperação internacional e de acordo com a organização e recursos de cada Estado, dos direitos econômicos, sociais e culturais indispensáveis à sua dignidade e ao livre desenvolvimento da sua personalidade

No Brasil, o direito ao desenvolvimento é um direito fundamental, sendo ele um dos emblemas contidos no preâmbulo da constituição, dessa forma a 


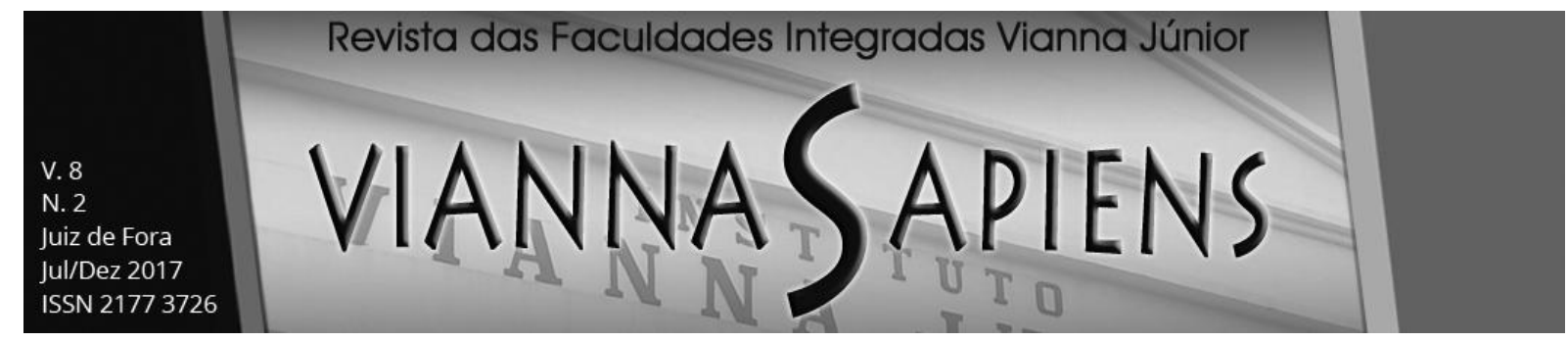

"constituição-cidadã" (BRASIL, 1988) visa a assegurar a efetivação do desenvolvimento, bem como diversos direitos. A palavra "desenvolvimento" é citada mais de setenta vezes no texto dessa constituição, dando a esse direito suma importância na elaboração e na aplicação de normas e na promoção dele. No artigo quinto, por um rol exemplificativo, estão previstos os direitos protegidos pelo Brasil, aos brasileiros e aos estrangeiros residentes no país, e em suas legislações supraconstitucionais. O direito ao desenvolvimento é citado nos incisos XXVI (desenvolvimento rural)e XXIX (desenvolvimento tecnológico e econômico).

Outro documento, que resguarda esse direito, é a "Declaração sobre o Direito ao Desenvolvimento", desenvolvida pela Assembleia Geral das Nações Unidas em 1986. A declaração, em seu primeiro artigo, determina que o direito ao desenvolvimento é um direito inalienável, ou seja, não pode ser suprimido das vidas das pessoas, também, o artigo delimita que cada indivíduo tem direito "a participar do desenvolvimento econômico, social, cultural e político, para ele contribuir e dele desfrutar, no qual todos os direitos humanos e liberdades fundamentais possam ser plenamente realizados" (ASSEMBLEIA GERAL DAS NAÇÕES UNIDAS, 1986).

Em seus dez artigos, a declaração explana sobre os deveres que cada Estado tem perante a população, à medida que ele deve fomentar políticas de desenvolvimento da nação e proteção dos direitos humanos. Ademais, o documento resguarda a pessoa humana, ao atribuir a cada indivíduo a proteção dos seus direitos e, consequentemente, do seu desenvolvimento. Por conseguinte, a “Declaração sobre o Direito ao Desenvolvimento" zela pelos dois aspectos do direto ao desenvolvimento: o desenvolvimento do indivíduo e o desenvolvimento da nação (ASSEMBLEIA GERAL DAS NAÇÕES UNIDAS, 1986).

Nas Américas, a Convenção Americana sobre Direitos Humanossó faz uma menção ao desenvolvimento no artigo 26. O documento prevê que os Estados signatários devem adotar providências, internas e de cooperação internacional, para efetivamente aplicarem os direitos econômicos, sociais e sobre educação, ciência e cultura previstos na Carta da Organização dos Estados Americanos. Portanto, são diversos documentos que consagram e protegem o direito ao desenvolvimento no 


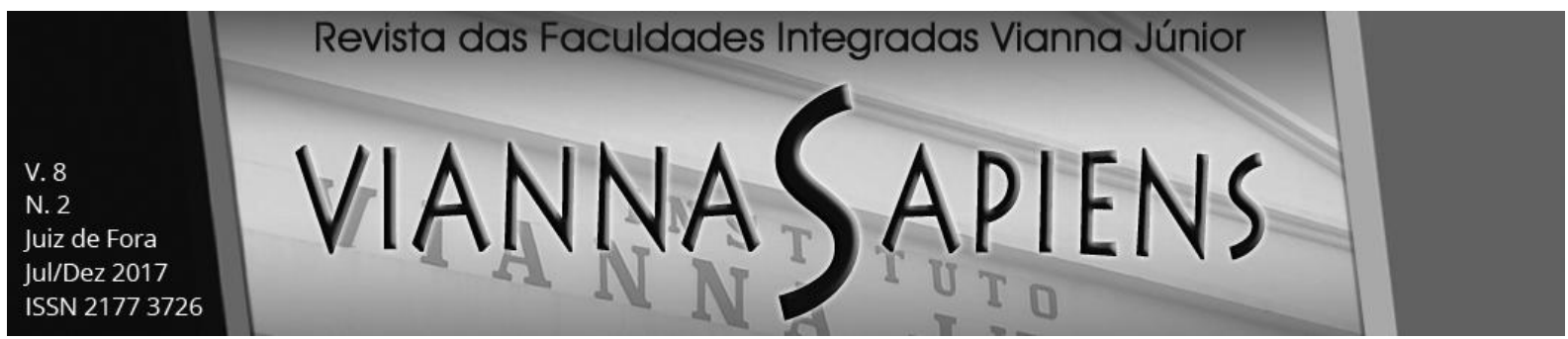

âmbito internacional e no aspectro regional, concedendo-lhe o status de direito humano, e, no caso do Brasil, a carta magna transforma o desenvolvimento em um direito fundamental (COMISSÃO INTERAMERICANA DE DIREITOS HUMANOS, 1969).

Após a previsão do direito ao desenvolvimento, começou-se a estudar diversos aspectos dele, como o objetivo, os sujeitos protegidos, dentre outros. Sobre os detentores e os protetores desse direito, o autorHector GrosEspiell, na obra "EI derecho al desarrollo como um derecho de La persona humana" (1980), defende que o direito ao desenvolvimento é

caracterizado como un derecho colectivo, cuyos titulares o sujetos activos eran personas jurídicas de diversa naturaleza (Estados, pueblos, regiones, provincias, municipios, etc.) y en el que los sujetos pasivos o deudores de las obligaciones que de su reconocimiento resultaban, eran el Estado, los países desarrollados y la Comunidad Internacional

Além disso, o autor determina que os indivíduos são os sujeitos ativosdesse direito, os quais seriam cada pessoa integrante de uma nação, como também, aqueles que não detêm nenhuma nacionalidade. Quanto à finalidade, Robério Nunes dos Anjos Filho apud resolução número 2.626 (ASSEMBLEIA GERAL DAS NAÇÕES UNIDAS, 1970) afirma que o objetivo é a expansão do bem-estar do indivíduo e da coletividade. Tendo em vista todos os documentos que citam e protegem o direito ao desenvolvimento e todas suas características, é possível conceituá-lo como a síntese de todos os direitos humanos (ESPIELL, 1970), no qual "involves the realisation of all the civil, political, economic, social and cultural rights, and therefore all the characteristics of the State obligations apply equally to its implementation" (p. 75, SENGUPTA; NEGI; BASU, 2005).

Como citado, o direito ao desenvolvimento subdivide-se, doutrinariamente, em dois âmbitos, o desenvolvimento do indivíduo e o desenvolvimento da nação. $O$ desenvolvimento do indivíduo trata do progresso individual de cada ser humano, que só pode se desenvolver tendo seus direitos humanos protegidos e respeitada sua 


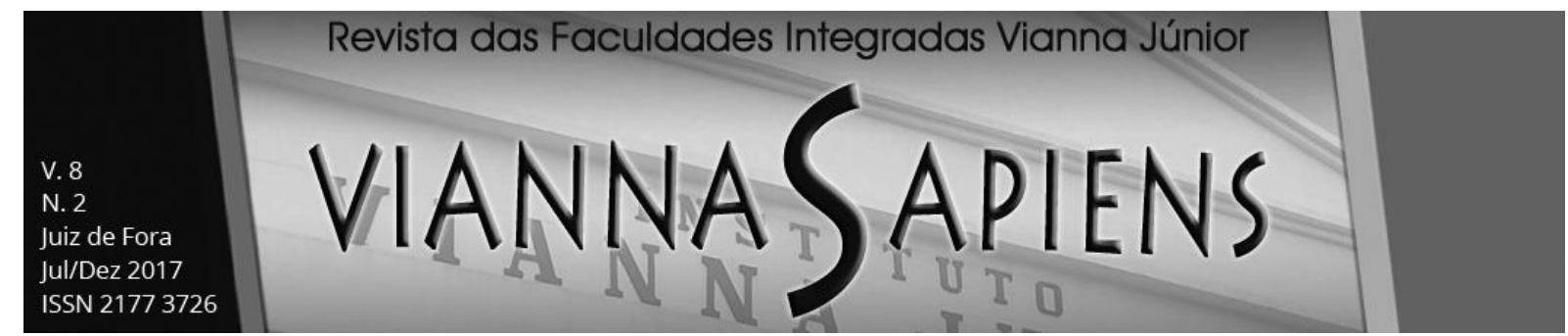

dignidade da pessoa humana. Esse âmbito e os conceitos serão trabalhados, profundamente, na terceira parte do artigo.

Atrelado ao direito ao desenvolvimento, está o Índice de Desenvolvimento Humano (IDH), que consiste em uma forma de ponderação do progresso de uma nação por meio de três aspectos (renda, saúde e educação). Esse índice foi desenvolvido por Mahbub ul Haq e pelo economista indiano AmartyaSen, havendo, como um dos propósitos, fomentar o debate da situação de cada país avaliado (PNUD BRASIL, 2017).

Por meio desse índice, discute-se se um país rico é um país desenvolvido, pois, diversas vezes, somente uma parte da população possui uma vida digna e tem seus direitos humanos aplicados, enquanto a outra porção da sociedade vive de maneira degradante e indigna. Essa desigualdade social também é analisada pelo Índice Gini, que mede o grau de concentração de renda em determinado país (WOLFFENBÜTTEL, 2004). Esses dois índices estão relacionados a um dos âmbitos do direito ao desenvolvimento, o desenvolvimento da nação, que será trabalhado na segunda parte do presente trabalho.

\section{O DIREITO AO DESENVOLVIMENTO DA NAÇÃO}

Nessa parte do trabalho, será desenvolvido um estudo sobre o direito ao desenvolvimento da nação, que está atrelado ao desenvolvimento econômico, porém não está ligado somente a esse segmento. Esse direito abrange o progresso humano, com todas suas variáveis, que pode agrupar o econômico ou ser distinto dele. Outro aspecto, a ser trabalhado é o desenvolvimento igualitário, ou seja, de todos os segmentos sociais, desde os mais pobres aos mais ricos. Esse desenvolvimento, de toda a nação, reduz a desigualdade social e não possibilita que um grupo tenha todos os recursos para se desenvolver, enquanto outros têm diversos direitos humanos violados. 


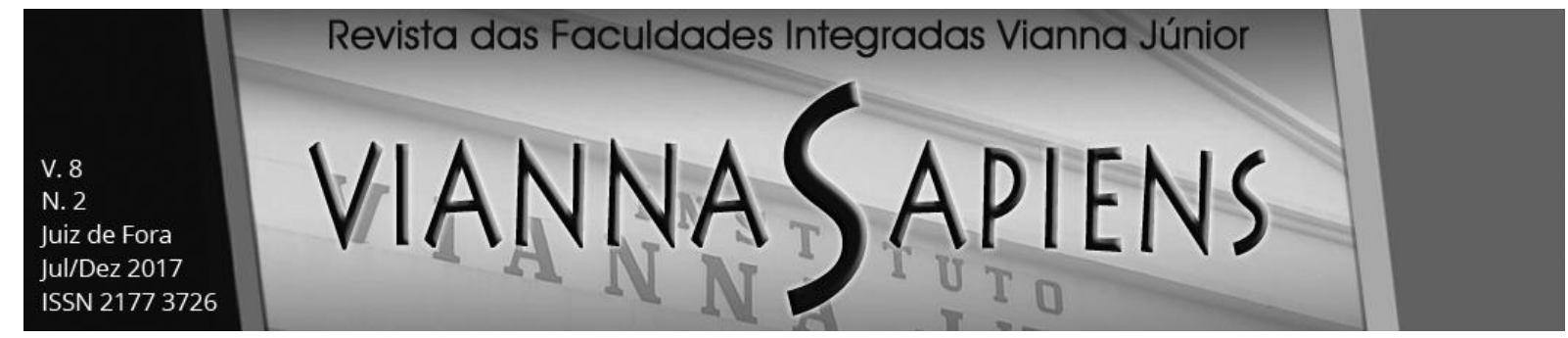

Como citado, o Índice de Desenvolvimento Humano (IDH) foi desenvolvido por Mahbub ul Haq e pelo economista indiano AmartyaSen, que, de acordo com a United Nations Development Programme (2016), esse índice avalia o desenvolvimento de um país e não somente o crescimento econômico. O Índice de Desenvolvimento Humanoé dividido em três dimensões: a longevidade e uma vida saudável, o conhecimento e um padrão de vida decente.

Cada uma dessas dimensões é calculada por meio de indicadores e nomeada como um dos indicadores do calculo do indicador, a saúde, a educação e a renda. $A$ saúde, é calculada com base na expectativa de vida da população ao nascer, já a educação é baseada na quantidade de anos escolares frequentados por adultos com 25 anos ou mais e na expectativa da quantidade de anos escolares para crianças em idade escolar. Por fim, a renda é medida pelo coeficiente GINI, que valia o desvio na distribuição de renda entre indivíduos ou famílias dentro de um país. Essas três dimensões compõem o Índice de Desenvolvimento Humanopor meio de uma média geométrica (UNITED NATIONS DEVELOPMENT PROGRAMME, 2016).

O último cálculo do Índice de Desenvolvimento Humanofoi realizado em 2015. No ranking, a Noruega $(0,949)$, a Austrália $(0,939)$, a Suíça $(0,939)$, a Alemanha $(0,926)$, a Dinamarca $(0,925)$, Cingapura $(0,925)$, a Holanda $(0,924)$, a Irlanda $(0,923)$, a Islândia $(0,921)$, o Canadá $(0,920)$ e os Estados Unidos $(0,920)$ ocuparam as dez primeiras colocações. Em relação ao Brasil, o país ocupou a 79a posição no ranking, sendo que seu índice foi de 0,754, tendo como expectativa de vida 74,7 anos, 15,2 anos esperados de escolaridade, a quantidade de anos escolares frequentados por adultos com 25 anos ou mais foi de 7,8 anos, e o coeficiente GINI per capita (2011) foi de 14,145 (UNITED NATIONS DEVELOPMENT PROGRAMME, 2015).

O índice foi dividido em diversas faixas:desenvolvimento humano muito alto, nessa faixa, estariam os dez países citados e todos aqueles que têm o IDH superior a 0,800; desenvolvimento humano alto, na qual se encontra o Brasil e países como Costa Rica e Venezuela e todos que possuem IDH superiores a 0,700; 


\section{Revista das Faculdades Integradas Vianna Júnior \\ VIANNASAPIENS}

desenvolvimento humano médio, em que se encontram países como Indonésia, Palestina, Iraque e Paraguai, como todos os que detêm IDH superiores a 0,550; e desenvolvimento humano baixo, nessa última faixa, estariam os países que obtiveram os menores IDH, tais como a Nigéria, Angola, Haiti, Sudão e Afeganistão (UNITED NATIONS DEVELOPMENT PROGRAMME, 2015).

No último IDH, cada região obteve a seguinte pontuação: a África subsaariana (0,523), a Ásia do Sul $(0,621)$, os Estados árabes $(0,687)$, a Ásia Oriental e o Pacífico $(0,720)$, a América Latina e o Caribe $(0,751)$ e a Europa e a Ásia Central $(0,756)$. A América Latina, região que integra o Brasil, obteve a segunda colocação no IDH por regiões (UNITED NATIONS DEVELOPMENT PROGRAMME, 2015).

Portanto, o IDH foi de suma importância para o crescimento do estudo do direito ao desenvolvimento, pois, com ele, "o foco é transferido do crescimento econômico, ou da renda, para o ser humano" (PNDU BRASIL, 2017). Também, o índice é uma forma de constatação das condições do desenvolvimento de cada país e é base para a elaboração de condições para o desenvolvimento humano, como a participação na vida política e comunitária, a sustentabilidade ambiental, a segurança, a promoção da igualdade, da justiça social e dos direitos humanos (UNITED NATIONS DEVELOPMENT PROGRAMME, 2016).

Antigamente, o direito ao desenvolvimento era atrelado somente ao desenvolvimento econômico. Com a evolução nos estudos dessa área, atualmente, a economia é uma parte do direito ao desenvolvimento e compõe a evolução do ser humano. Esse segmento é mensurado pelo índice GINI, que compreende uma representação do "deviation of the distribution of income among individuals or households within a country from a perfectly equal distribution" (UNITED NATIONS DEVELOPMENT PROGRAMME, 2013). Os países estudados pelo índice são classificados entre zero e cem, no qual zerorepresenta igualdade absoluta, e cem representa desigualdade completa.

O último índice divulgado foi em 2013. Dentre os dez países com menos desigualdade estavam: Suécia (25.0), Ucrânia (25.6), Noruega (25,8), Eslováquia (26.0), Bielorrússia (26,5), Finlândia (26.9), Romênia (27.4), Afeganistão (27.8), 


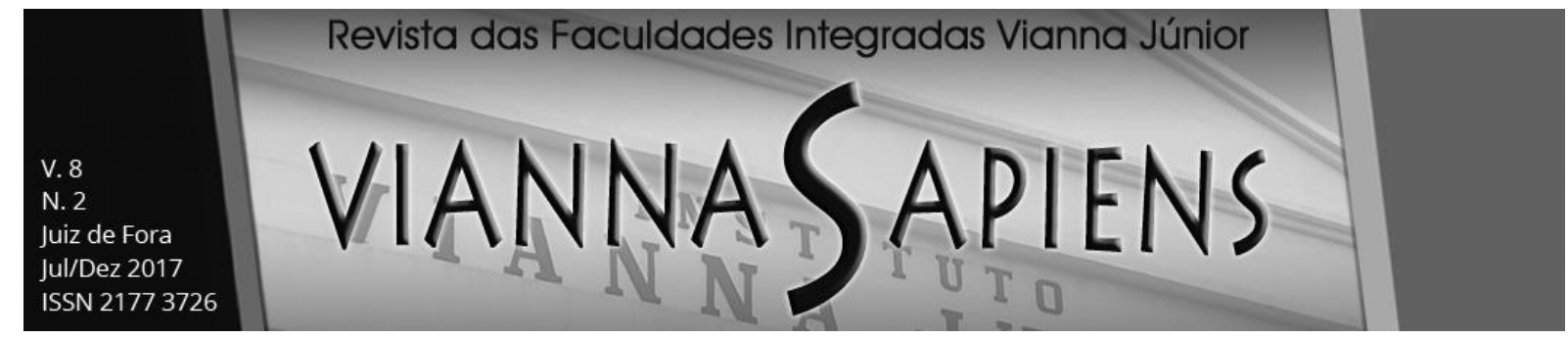

Bulgária (28.2) e Alemanha (28.3). Dos países citados, somente dois (Noruega e Alemanha) estavam entre os dez países com maior IDH, enquanto outros, como o Afeganistão, obtiveram a colocação 169 no IDH. Essa disparidade demonstra que um país sem desigualdades pode não ser um país desenvolvido, por isso a educação e a saúde, como diversos outros indicadores, devem ser utilizados para determinar se um país é desenvolvido humanamente ou não (UNITED NATIONS DEVELOPMENT PROGRAMME, 2013).

Outro indicador de que um país rico pode não ser um país desenvolvido é o Produto Interno Bruto (PIB), que consiste em um "somatório de todos os bens e serviços finais produzidos dentro do território nacional num dado período, valorizados a preço de mercado" (p. 154, VASCONCELLOS, GARCIA, 2008). Como demonstrado na tabela 1, os indicadores econômicos (PIB e GINI) não possibilitam a comprovação do desenvolvimento humano, que está atrelado ao objeto desse estudo: o direito ao desenvolvimento. Em razão de que, dentre os dez países com maior PIB em 2016, está a Índia, que obteve a 131ํㅡㄹ colocação no IDH em 2015, e o Brasil, que teve a 126 posição no ranking do GINI (2013), um dos indicadores do IDH. Por isso, eles (PIB e GINI) deixaram de ser considerados índices de desenvolvimento humano e passaram a demonstrar, somente, o desenvolvimento econômico.

Tabela 1 - Ranking PIB em comparação ao ranking GINI e IDH

$\begin{array}{ccccccc}\text { País } & \begin{array}{c}\text { PIB (2016) - (Milhões } \\ \text { de dólares americanos) }\end{array} & \begin{array}{c}\text { Ranking } \\ \text { PIB (2016) }\end{array} & \begin{array}{c}\text { GIN } \\ \text { I }\end{array} & \begin{array}{c}\text { Ranking } \\ \text { GINI (2013) }\end{array} & \begin{array}{c}\text { IDH } \\ (2015)\end{array} & \begin{array}{c}\text { Ranking } \\ \text { IDH } \\ (2015)\end{array} \\ \text { Estados Unidos } & 18.569 .100 & 1 & 40,8 & 83 & 0,920 & 10 \\ \text { China } & 11.199 .145 & 2 & 42,1 & 89 & 0,738 & 90 \\ \text { Japão } & 4.939 .384 & 3 & \ldots & \ldots & 0,903 & 17 \\ \text { Alemanha } & 3.466 .757 & 4 & 28,3 & 2 & 0,926 & 4 \\ \text { Reino Unido } & 2.618 .886 & 5 & 36,0 & 51 & 0,909 & 16 \\ \text { França } & 2.465 .454 & 6 & \ldots & \ldots & 0,897 & 21\end{array}$




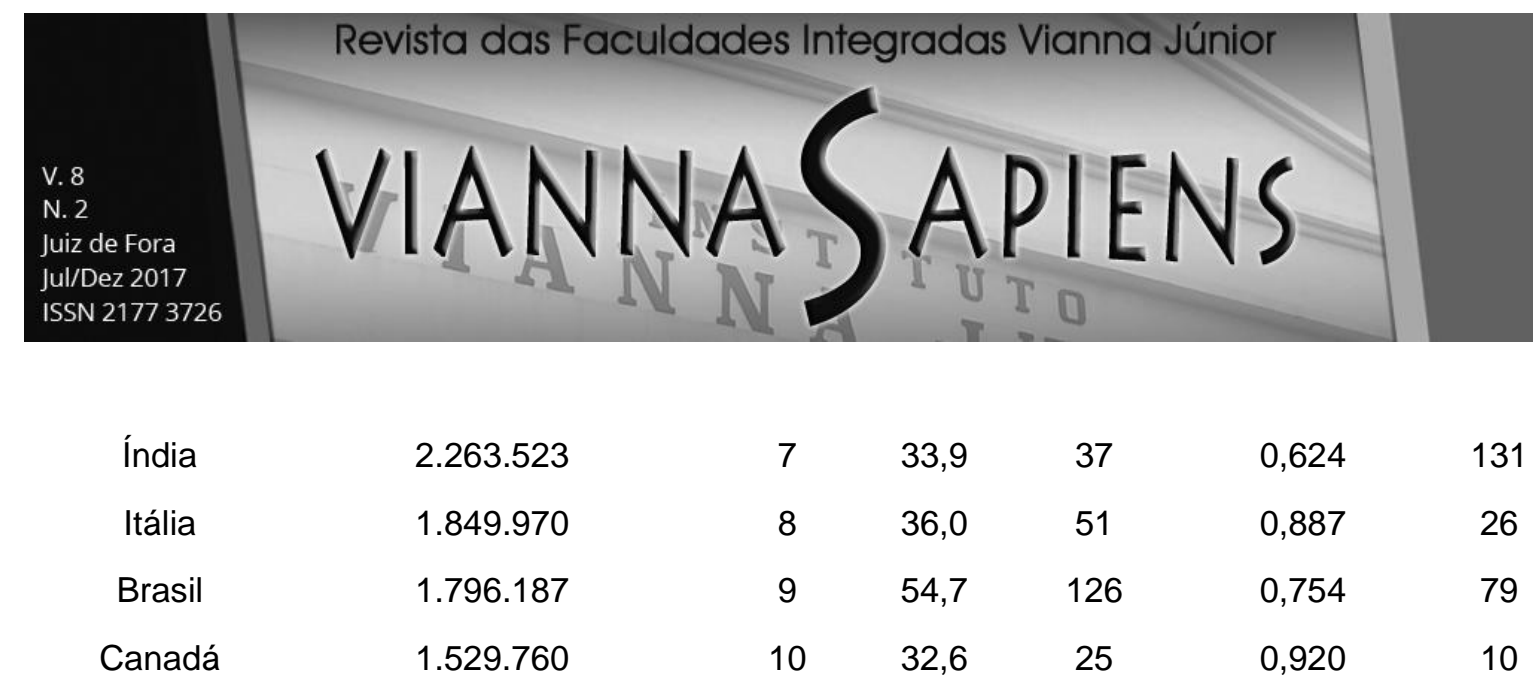

Fonte: WORLDBANK, 2016, UNITED NATIONS DEVELOPMENT PROGRAMME, 2013 e UNITED NATIONS DEVELOPMENT PROGRAMME, 2015.

Em vista dessa mudança, para melhor demonstrar o desenvolvimento humano, foi criado o IDH, que fora explicado anteriormente e pretende certificar as condições de desenvolvimento humano. Para analisar os níveis de desenvolvimento dentro dos países, criou-se o IDH Municipal (IDHM). No caso do Brasil, o país tem dimensões continentais, portanto algumas regiões desenvolvem-se melhor que outras. O Programa das Nações Unidas para o Desenvolvimento (PNUD) Brasil, o Instituto de Pesquisa Econômica Aplicada e a Fundação João Pinheiro desenvolveram esse estudo em 2010 com dados de três Censos Demográficos do Instituto Brasileiro de Geografia e Estatística (IBGE) (1991, 2000 e 2010), criando o "Atlas do Desenvolvimento Humano no Brasil" (2010).

A finalidade do IDHM brasileiro é "ajustar a metodologia (do IDH) ao contexto brasileiro, buscando indicadores mais adequados para avaliar as condições de núcleos sociais menores - os municípios" (ATLAS DO DESENVOLVIMENTO HUMANO DO BRASIL, 2010). Ele é calculado com as mesmas estatísticas do IDH global, exceto a dimensão renda, que é calculada pela renda municipal per capita, como, também, possui as mesmas faixas de qualificação do desenvolvimento humano, com exceção das faixas baixo $(0,599$ a 0,500$)$ e muito baixo $(0,499$ e pontuações inferiores). A pesquisa foi dividida em Unidades de Desenvolvimento Humano (UDHs), que são regiões administrativas, regionais, distritos, subprefeituras, inframunicipais (como bairros), que são agregações das UDHs em várias escalas (ATLAS DE DESENVOLVIMENTO HUMANO, 2010). 


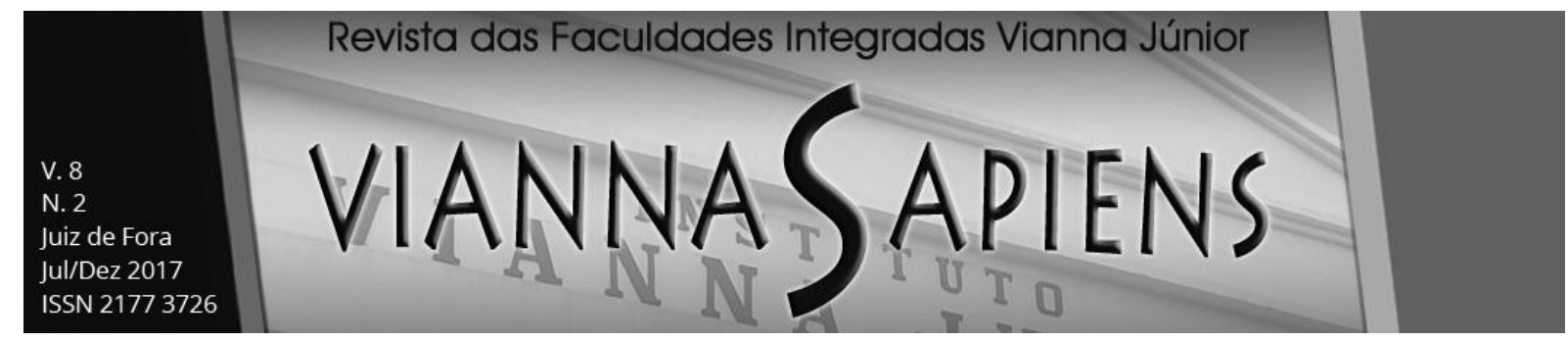

No ranking de 2010, no âmbito município, a cidade de São Caetano do Sul, em São Paulo, obteve a primeira colocação com a pontuação de 0.862 , em contrapartida, Melgaço, no Pará, ficou como última colocada, com IDHM de 0.418 (ATLAS DE DESENVOLVIMENTO HUMANO, 2010). A diferença entre essas duas cidades é demonstrada em uma comparação ao IDH global, a cidade de São Paulo teve aproximadamente o IDH da Estônia (0.865), na Europa, que foi a 30ª coloca no ranking global. Melgaço pode ser comparada a Moçambique $(0,418)$ e Sul do Sudão $(0,418)$, na África, que foram os $181^{\circ}$ colocados dentre 188 países (UNITED NATIONS DEVELOPMENT PROGRAMME, 2015). Esse contraponto valida a ideia de que, dentro de um mesmo país, podemos ter o IDH de um dos trinta melhores países para se viver e dos sétimos piores países para se habitar.

A diferença entre municípios não constata a maior discrepância entre os mais pobres e os mais ricos, o ranking entre as menores UDHs expressa a maior desigualdade presente no Brasil. Berrini e Vila Funchal, localizadas na região metropolitana de São Paulo, que é composta por 39 municípios, obtiveram a primeira colocação com IDHM (0.965), juntamente com outras cinco regiões brasileiras (ATLAS DE DESENVOLVIMENTO HUMANO, 2010). O IDH dessas regiões foi superior ao da primeira colocada global, a Noruega, com 0,949 pontos (UNITED NATIONS DEVELOPMENT PROGRAMME, 2015). Por outro lado, a Zona Rural de Itacoatiara, região metropolitana de Manaus, que é composta de8 municípios, teve o IDHM de 0.501 e está na última colocação (ATLAS DE DESENVOLVIMENTO HUMANO, 2010). O IDH dessa zona iguala-se ao dos países Madagascar (IDH: 0,512 e 158ª posição) e Ruanda (IDH: 0.498 e 159a posição) (UNITED NATIONS DEVELOPMENT PROGRAMME, 2015).

No nível estadual, o Distrito Federal obteve a primeira colocação com IDHM 0.824, enquadrando-se na faixa de desenvolvimento humano muito alto. Já Alagoas ficou com a última colocação, com 0.631 pontos, estando na faixa de desenvolvimento humano baixo. Outro ranking são as regiões metropolitanas, a primeira colocação foi para São Paulo, com IDHM (0.794), e Maceió na última colocação, com IDHM (0.702) (ATLAS DE DESENVOLVIMENTO HUMANO, 2010). 


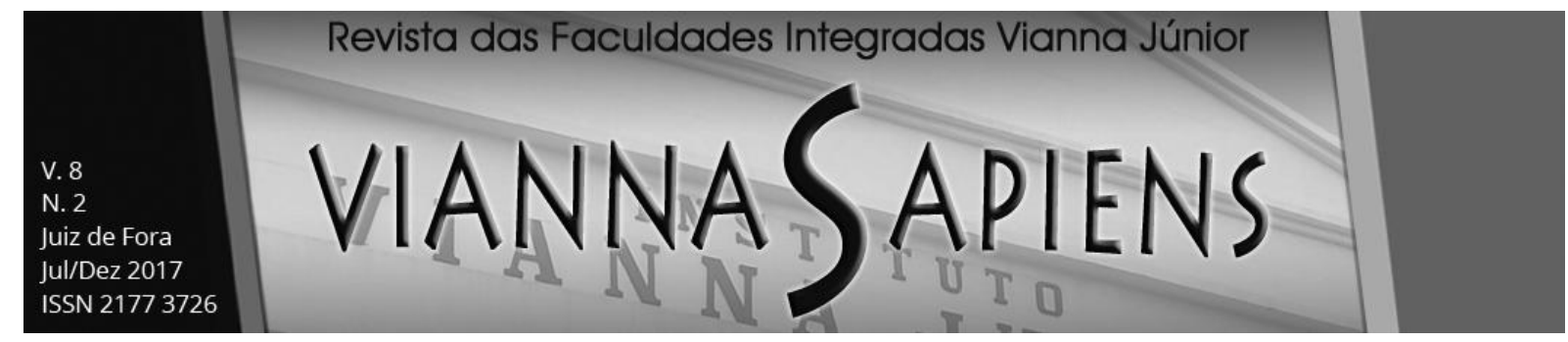

Dessa maneira, os índices, IDH, GINI, PIB e IDHM são algumas maneiras de demonstrar o desenvolvimento humano e econômico, porém eles não são formas perfeitas de demonstrar a situação real de cada país e suas regiões. Cada indicador tem sua importância, como o IDHM, que consegue verificar as desigualdades dentro de cada país, possibilitando a melhoria das situações mais precárias por meio de "políticas públicas no nível municipal a priorizar a melhoria da vida das pessoas em suas ações e decisões" (ATLAS DE DESENVOLVIMENTO HUMANO, 2010).

O direito ao desenvolvimento, antigamente, era relacionado somente ao crescimento econômico, por isso, os índices GINI e PIB eram utilizados para determinar se um país era desenvolvido ou não. Contudo, passa-se a perceber, que esse direito refere-se ao desenvolvimento "social, político, humano, econômico, ambiental, infantil, nacional, regional, equilibrado, sustentável, dentre muitos outros" (p. 17, ANJOS FILHO, 2013). Por isso, o IDH e o IDHM foram criados, em uma tentativa de demonstrar a real situação de desenvolvimento de cada país. De acordo com o Atlas do Desenvolvimento Humano no Brasil (2010), IDHM estuda o desenvolvimento das pessoas, não se limitando ao crescimento econômico, sendo assim um contraponto ao PIB.

Com essa mudança de desenvolvimento econômico para um desenvolvimento humano, começa-se a discutir a necessidade de políticas públicas voltadas ao desenvolvimento humano, ou seja, que aprimorassem diversos direitos humanos. A "Declaração sobre o Direito ao Desenvolvimento" (ASSEMBLEIA GERAL DAS NAÇÕES UNIDAS, 1986), no parágrafo terceiro do artigo segundo, prevê que "Estados têm o direito e o dever de formular políticas nacionais adequadas para o desenvolvimento, que visem ao constante aprimoramento do bem-estar de toda a população". Esse texto legal pode ser interpretado no plano internacional, sendo assim uma cooperação entre países, como, também, no plano nacional, que o governo deve fomentar o direito ao desenvolvimento a todos nacionais.

Sobre o espectro interno desse direito, ainda no artigo segundo da declaração referida (ASSEMBLEIA GERAL DAS NAÇÕES UNIDAS, 1986), essa norma fixa que 


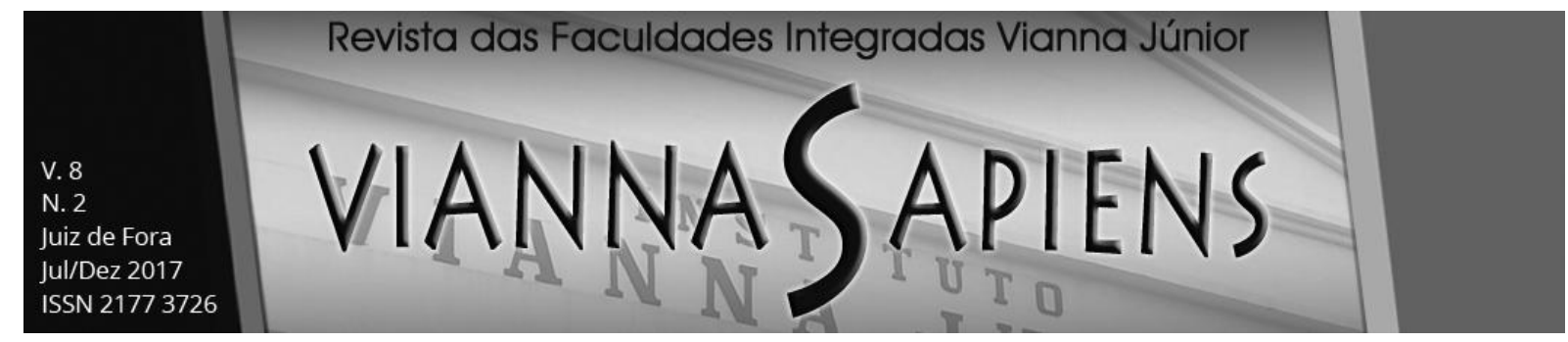

os Estados devem fomentar políticas baseadas "no desenvolvimento e na distribuição equitativa dos benefícios daí resultantes". Por esse motivo, o IDHM viabiliza o paralelo entre as realidades de distintas regiões e municípios brasileiros. Como versado por Robério Anjos Filho (p. 252, 2013), "o desenvolvimento não é uniforme entre as sociedades nem tampouco nas sociedades", por isso, o desenvolvimento dentro do Brasil não será igualitário em todo o território nacional, o que fora corroborado pelas disparidades entre as UDHs no IDHM.

Essa desigualdade tem, como um dos fatores, a existência, dentro de um mesmo território, de grupos distintos com necessidades diferentes, assim como de minorias sociais e de grupos marginalizados, que,normalmente, precisam de um auxílio maior do Estado para se desenvolver. Por isso, as políticas públicas voltadas ao desenvolvimento devem abordar as diferentes necessidades de cada segmento social, para criar uma sociedade mais justa e igualitária.

Outro ângulo do direito ao desenvolvimento foi explorado pelo parágrafo segundo do artigo primeiro da "Declaração sobre o Direito ao Desenvolvimento" (ASSEMBLEIA GERAL DAS NAÇÕES UNIDAS, 1986), que institui o direito dos povos à autodeterminação e o exercício de sua soberania plena sobre todos os seus recursos naturais e suas riquezas. Destarte, o direito objeto desse estudo possui inúmeras óticas, que podem ser utilizadas para diversos fins e, em um futuro, novas perspectivas serão geradas.

\section{O DIREITO AO DESENVOLVIMENTO DO INDIVÍDUO E SUA APLICAÇÃO}

O paradigma individual do direito ao desenvolvimento tem o foco no ser humano, conforme 0 artigo segundo da "Declaração sobre o Direito ao Desenvolvimento" (1986), "a pessoa humana é o sujeito central do desenvolvimento e deveria ser participante ativo e beneficiário do direito ao desenvolvimento", dessa forma é a principal beneficiária e participante. Ademais, o direito ao desenvolvimento do indivíduo é fundamentado pela dignidade da pessoa humana, por meio dos 


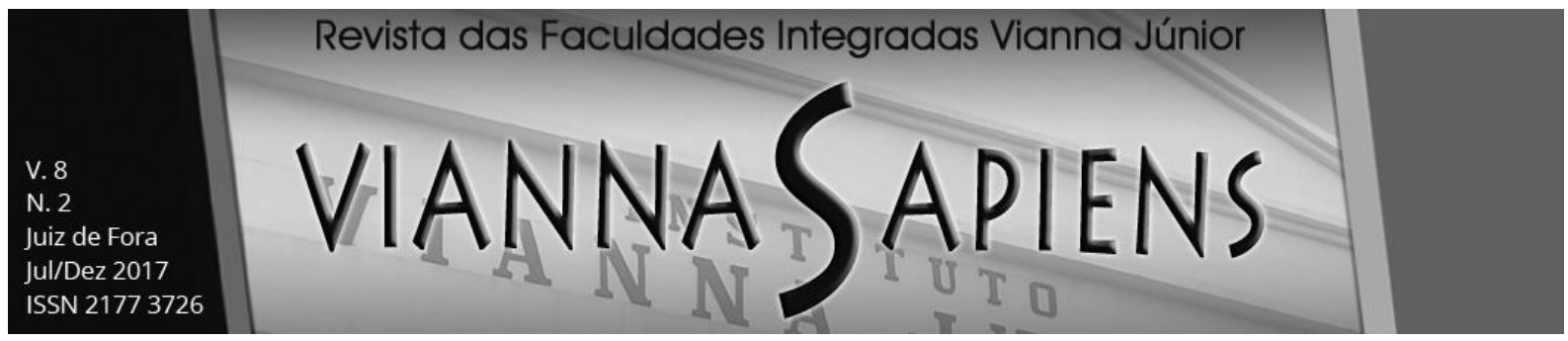

documentos citados neste trabalho, como a "Declaração Universal de Direitos Humanos" (ANJOS FILHO, 2013). Portanto, de acordo com a Declaração Universal de Direitos Humanos (1948), "todo ser humano, como membro da sociedade, tem direito [...] ao livre desenvolvimento da sua personalidade" nas duas fases desse direito, a coletiva e a individual, visto que, "afinal, coletividades são formadas por seres humanos" (ANJOS FILHO, 2013 p. 219).

Desse modo, cada indivíduo, integrante ou não de uma sociedade tem o direito a um desenvolvimento integral, "o que justifica o fato da promoção, do respeito e do gozo de certos direitos humanos e liberdades fundamentais não poderem justificar a negação de outros direitos humanos e liberdades fundamentais" (p. 220, ANJOS FILHO, 2013). Amartya Sen (2010), no seu livro "Desenvolvimento como liberdade", defende que o desenvolvimento seria uma forma de "expansão das liberdades reais que as pessoas desfrutam" (p. 16), assim sendo milhões de pessoas são privadas, diariamente, de inúmeras formas de liberdades, as fomes coletivas e a subnutrição, por exemplo, transgridem a liberdade da sobrevivência.

Sen (2010) cita alguns tipos de liberdades relevantes em seu livro, como o acesso à saúde, ao saneamento básico, às oportunidades (em seu sentido amplo e irrestrito), à educação, à um emprego remunerado, à segurança (tanto econômica como social), como, também, a desigualdade, entre homens e mulheres, é uma forma de privação ao desenvolvimento. O autor defende, que, muitas vezes, essas negações são explicadas por serem uma forma de estimular o rápido crescimento econômico, contudo não existem fortes indícios de que a privação de direitos individuais seria bom para o crescimento econômico de uma nação (SEN, 2010).

O crescimento de uma nação, no âmbito humano, teria como base 0 desenvolvimento do indivíduo, ao passo que o indivíduo desenvolvido tem sua liberdade de forma ampla e possui mais chances de obter resultados valiosos. Sendo assim, seu potencial é impulsionado, e as chances de influenciar mudanças externas (em seu bairro, em sua cidade ou em sua nação), assim como melhorias internas aumentam e promovem o desenvolvimento humano. Portanto, o direito ao desenvolvimento do indivíduo consistiria em uma "expansão das 'capacidades' 


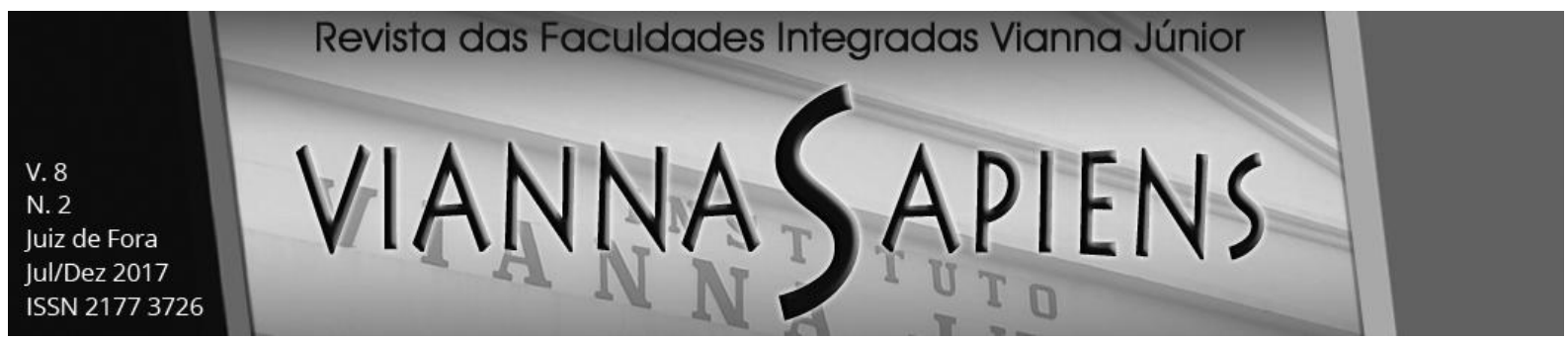

[capabilities] das pessoas de levar o tipo de vida que elas valorizam" (p. 33, SEN, 2010).

Para Robério Anjos Filho (2013), a igualdade de oportunidades para o desenvolvimento é crucial na dimensão individual do direito ao desenvolvimento e, por isso, os Estados passam a desempenhar o papel de fomentadores dessas oportunidades, seja no acesso a recursos básicos (como alimentação, saúde, moradia), seja na perspectiva profissional. Por isso, os Estados têm o dever de proporcionar todas as condições básicas para a pessoa desenvolver-se, o que pode ser feito por meio de políticas públicas, e encorajá-la a progredir, pois o desenvolvimento de um pode estimular o desenvolvimento da nação. Amartya Sen (2010) argumenta que as "liberdades" das pessoas são acrescidas pelas políticas públicas, mas é de suma importância a participação do povo para que essas políticas tenham efeitos e prosperem.

A igualdade de oportunidade citada também deve se estender de forma igual perante toda a população, desde os mais pobres aos mais ricos, o que já fora discutido no tópico sobre o direito ao desenvolvimento da nação. Com isso, um indivíduo nascido em uma família prestigiada tem mais oportunidades de se desenvolver, como também, possui mais liberdades e capacidades se comparado a uma pessoa que nasceu na classe mais baixa da sociedade.

Ademais, a redução da desigualdade é crucial para o desenvolvimento humano tanto do indivíduo quanto da nação, visto que, no caso do Brasil, os indivíduos que desfrutam de um IDH superior possuem segurança, mas essa noção de paz não é completa, pois sempre haverá a ameaça da violência (roubos e latrocínios) por meio das pessoas que têm uma vida com um IDH ruim, e essa coação, provavelmente, não existiria se eles também usufruirem um IDH bom. Dessa forma, quando o grupo mais pobre de uma sociedade desenvolve-se, toda a sociedade ganha ao melhorar o bem-estar de todos.

Dos países com maior PIB em 2016, de acordo com a "Tabela 1", somente a Alemanha atingiu as primeiras cinco colocações nos três índices (PIB - 2016, GINI 2013 e IDH - 2015), tendo, no aspecto desigualdade, o coeficiente dois. Na questão 


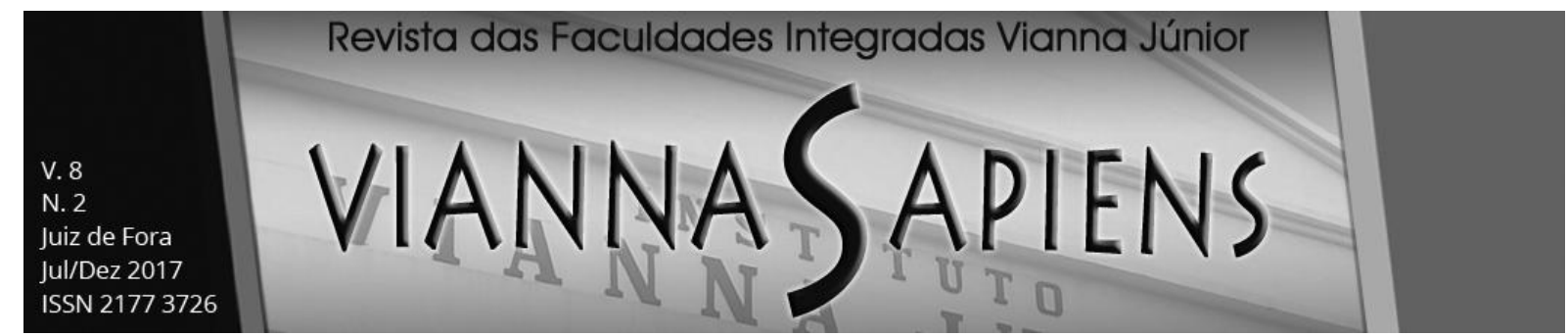

dos latrocínios (roubos seguidos de morte), no ano de 2014 (SINESP), foi registrada uma taxa de 0,87 (por 100 mil habitantes) desse crime no Brasil. Enquanto, na Alemanha, em 2015 (BKA), foram registrados 2.116 casos no gênero homicídio, latrocínio, homicídio sexual e homicídio culposo. A desigualdade não é o único fator que influencia essas estatísticas, todavia é um dos agentes que causa essa disparidade.

Com a intenção de efetivar o direito ao desenvolvimento, os países membros da ONU desenvolveram a "Declaração do Milênio" (2000), que seriam objetivos para extirpar a miséria, a mortalidade, a desigualdade, dentre outros temas, isto é, formas de privação das liberdades individuais e incompatíveis com a proteção do direito ao desenvolvimento. Foram criados oito "Objetivos de Desenvolvimento do Milênio", os “ODM"(ODM BRASIL, 2000):

acabar com a fome e a miséria; oferecer educação básica de qualidade para todos; promover a igualdade entre os sexos e a autonomia das mulheres; reduzir a mortalidade infantil; melhorar a saúde das gestantes; combater a Aids, a malária e outras doenças; garantir qualidade de vida e respeito ao meio ambiente; estabelecer parcerias para o desenvolvimento

No caso do Brasil, foi formulada uma "Agenda de Compromissos dos ODM", que, desde a criação dos objetos busca, por meio de programas e políticas públicas, objetiva melhorar o desenvolvimento do país. No quesito erradicação da pobreza e da fome, o programa Bolsa Família, o Sistema Único de Assistência Social e o Programa de Aquisição de Alimentos foram originados e/ou fomentados. Já em relação à educação, tenta-se universalizar o atendimento escolar, como, também, ampliar a oferta de educação infantil e em tempo integral. Sobre a igualdade entre sexos, impulsionou-se a autonomia econômica das mulheres, por meio da Organização Produtiva das Mulheres Rurais, do Programa Pró-Equidade de Gênero e Raça, do Programa Trabalho e Empreendedorismo da Mulher, entre outros (ODM BRASIL, 2013). 


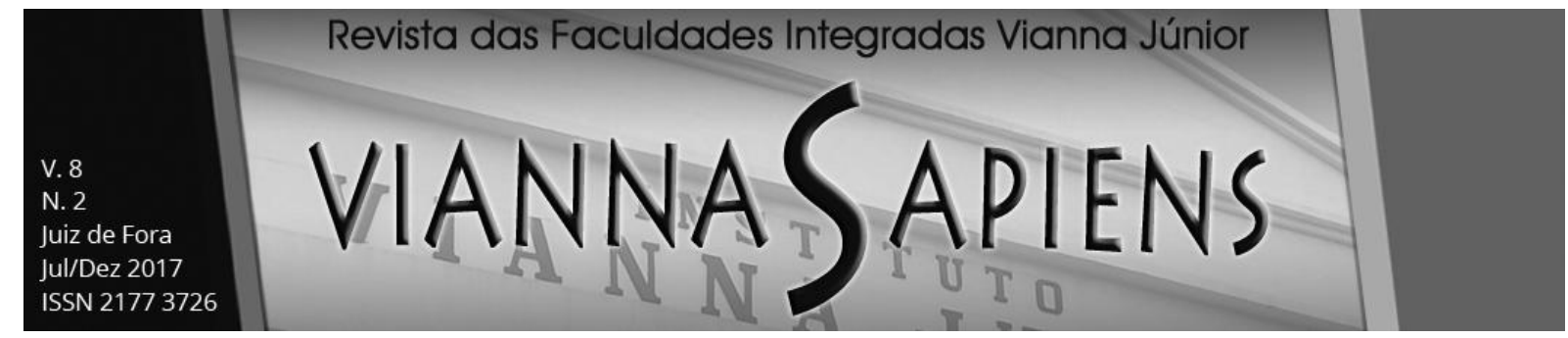

O quarto objetivo, reduzir a mortalidade infantil, foi possível por meio de imunizações e da política "Saúde Mais Perto de Você". Também, foi desenvolvida a Rede Cegonha (que engloba ações voltadas ao pré-natal, aos partos normais e à mortalidade materna) para fomentar o ODM 5. Já no combate a doenças sexualmente transmissíveis (DST), AIDS, malária, entre outras, foram criados Programas Nacionais de Controle. No quesito sustentabilidade, trabalhado pelo ODM 7, o abastecimento de água e o esgotamento sanitário foram formas para garantir a sustentabilidade ambiental. O oitavo objetivo foi desenvolvido pelo "Programa Microempreendedor Individual", o esforço fiscal, dentre outros. Com esses programas, o Brasil conseguiu melhorar o IDH nacional e, consequentemente, reduzir as distinções entre oslocais mais pobres e os mais ricos (ODM BRASIL, 2013).

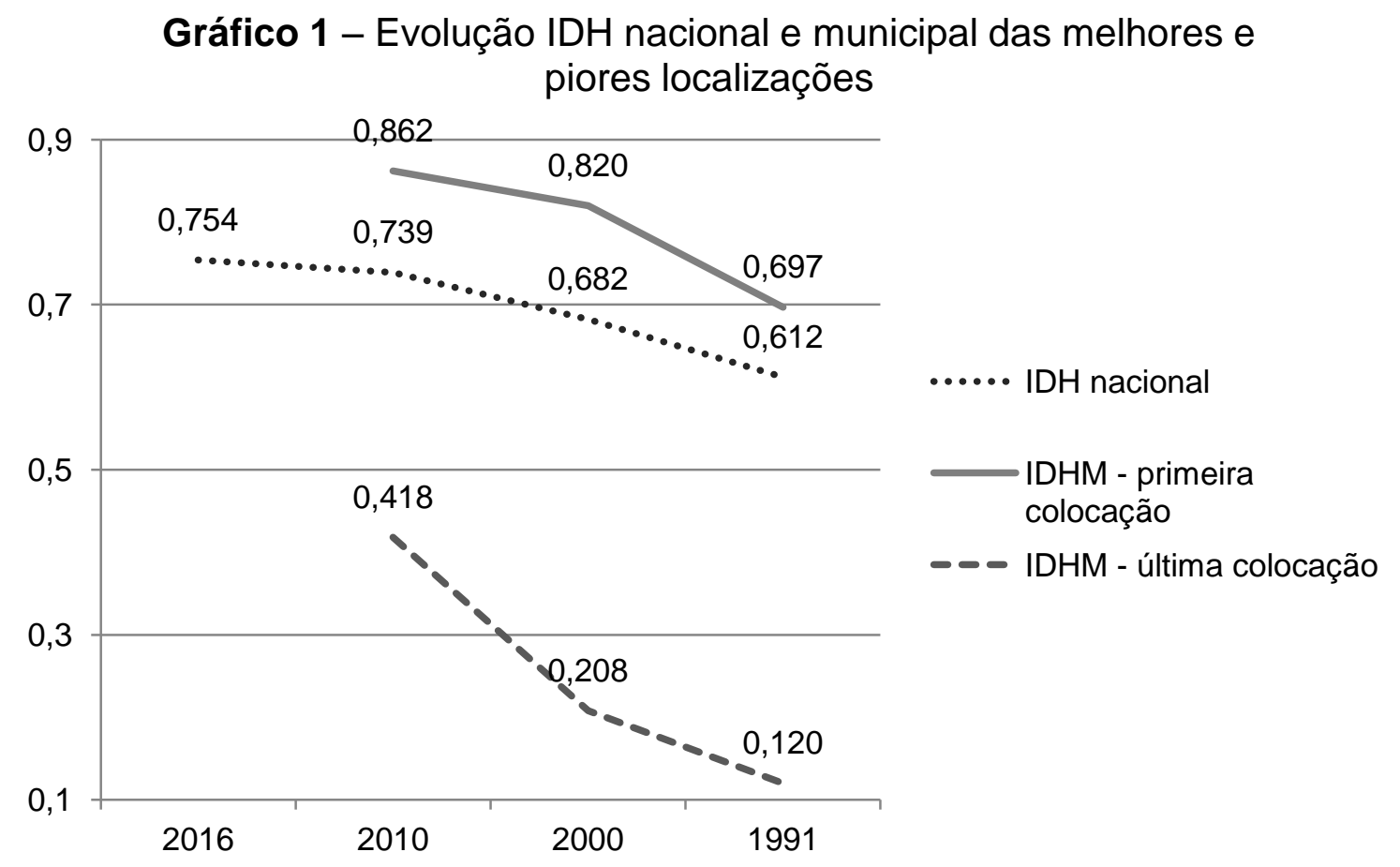

Fonte: ATLAS DE DESENVOLVIMENTO HUMANO, 2010, SENADO FEDERAL, 2013. 


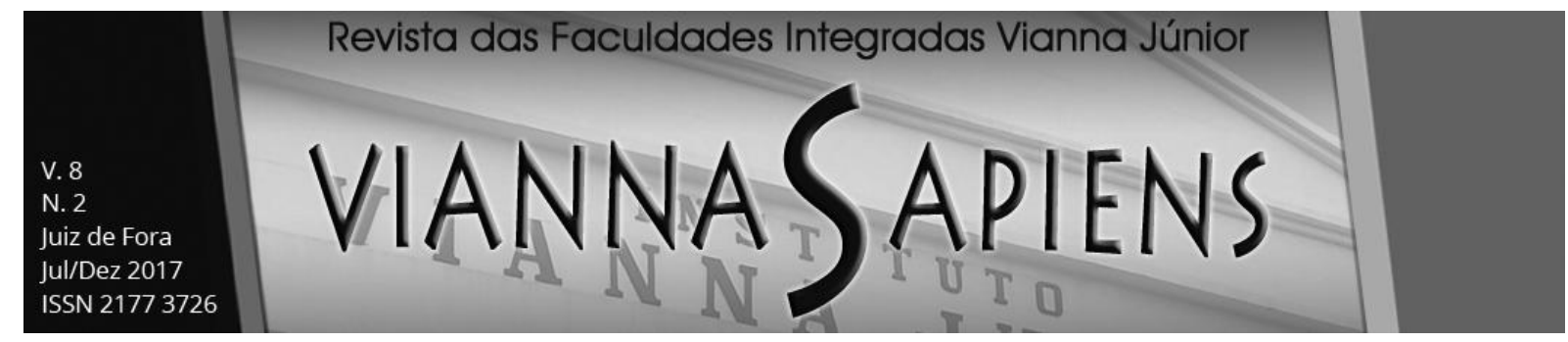

A fim de tornar cada nação e pessoa do mundo passíveis de se desenvolver, os Estados-membros da ONU, em 2015, atestaram que a pobreza é o maior desafio global e sua erradicação seria um requisito imprescindível para a efetivação do direito ao desenvolvimento. Isso posto, eles desenvolveram a "Agenda 2030", que consiste em uma agenda global de desenvolvimento, ou seja, é um plano de ação com "medidas ousadas e transformadoras para pôr o mundo em um caminho sustentável e robusto - sem deixar ninguém para trás". São 17 Objetivos de Desenvolvimento Sustentável, os "ODS", e 169 metas com a finalidade de acabar com a pobreza, garantindo o bem-estar de todos os seres humanos sem degradar o planeta. Os objetivos atingem as áreas fundamentais para o desenvolvimento humano integral, e são eles (PNUD BRASIL, 2015):

Figura 1 -17 Objetivos de Desenvolvimento Sustentável
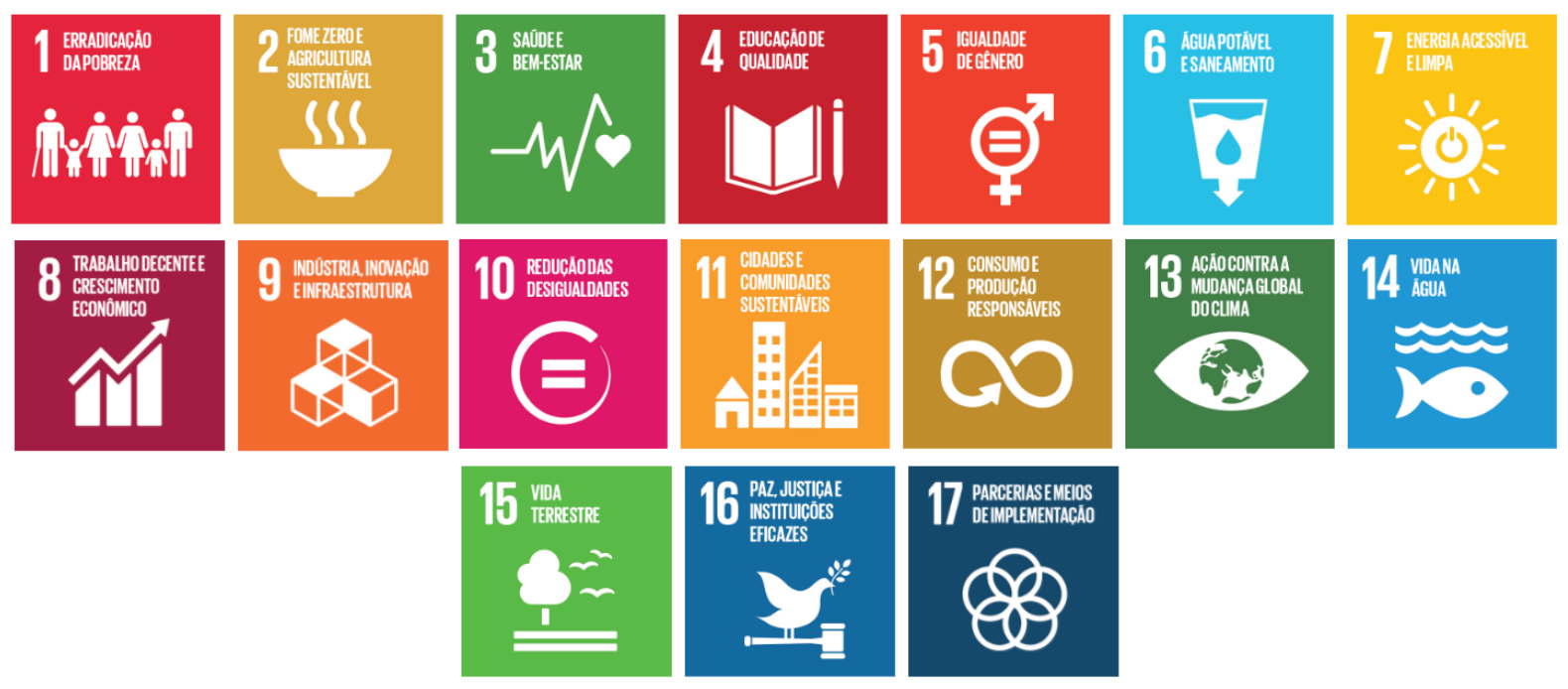

Fonte: PNUD BRASIL, 2015.

Para discutir a aplicação, a evolução e os rumos do direito ao desenvolvimento, existe a Conferência das Nações Unidas para Comércio e Desenvolvimento (UNCTAD - United Nations Conference on Trade and Development), que acontece a cada quatro anos, desde 1964, e está na décima quarta edição (UNCTAD, 2014). A cada quadriênio, uma cidade sedia a conferência, 


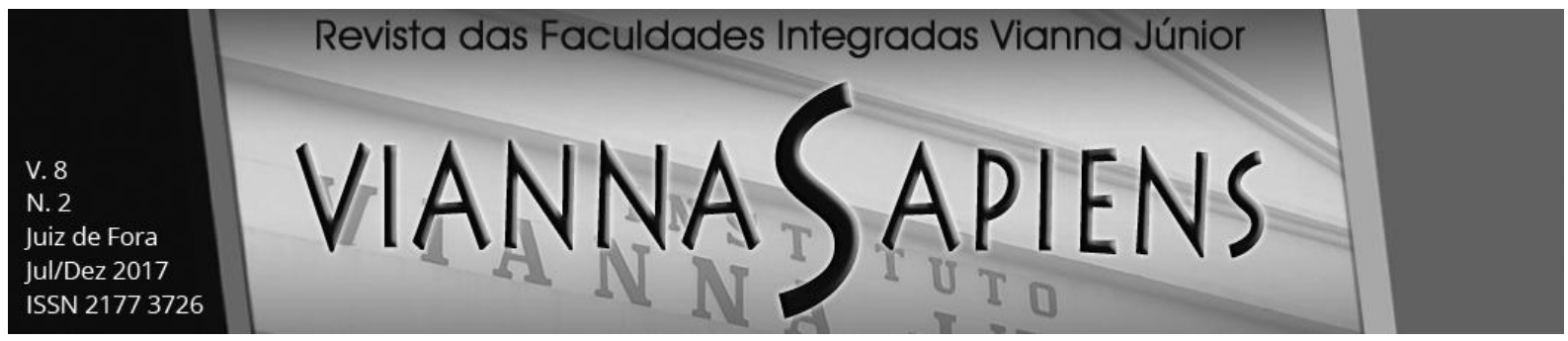

dentre elas estão Accra (Gana), Banguecoque (Tailândia), Midrand (África do Sul), Cartagena (Colômbia), Genebra (Suíça), Belgrado (Sérvia), Manila, (Filipinas), Nairobi (Quênia), Santiago (Chile) e Nova Deli (Índia). Concedendo uma ênfase, a décima primeira conferência foi sediada em São Paulo, no ano de 2004, e o secretário geral da UNCTAD, Rubens Ricupero (2004), discorreu sobre as questões principais da XI edição,que seriam "explore how to harness the power of trade for development and poverty reduction. [...] Even in those few areas where developing countries have acquired meaningful market access through global trade negotiations". Ainda de acordo com Ricupero (2004), a missão central dessa conferência era formar uma ligação dentre comércio e desenvolvimento.

Sobre a última conferência realizada, ela aconteceu em julho de 2016 na cidade de Nairobi (Quênia), a qual já havia sido sede da UNCTAD e teve como principais eventos: "world investment forum, global commodities forum, civil society forum, youth forum"; e temas: "transforming economies for sustainable and inclusive growth, building economic resilience for the most vulnerable, bolstering public policies for vibrant and inclusive markets, promoting a global environment for prosperity for all, marking innovation a driver for sustainable development, fostering Africa's structural transformation" (UNCTAD, 2016). A conferência é de suma importância para a discussão e a evolução de políticas para a aplicação desse direito, visto que ela apresenta a situação atual de diversos países e as maneiras como eles poderiam se desenvolver.

\section{CONCLUSÃO}

Após o presente estudo, podemos constatar algumas conclusões, como o sentido errôneo que era concedido ao direito ao desenvolvimento. Outrora, esse direito já foi denominado direito ao desenvolvimento econômico, pois só agrupava políticas e estudos voltados à economia, e esse segmento social era norteador dos índices de desenvolvimento. Atualmente, o desenvolvimento econômico não é mais 


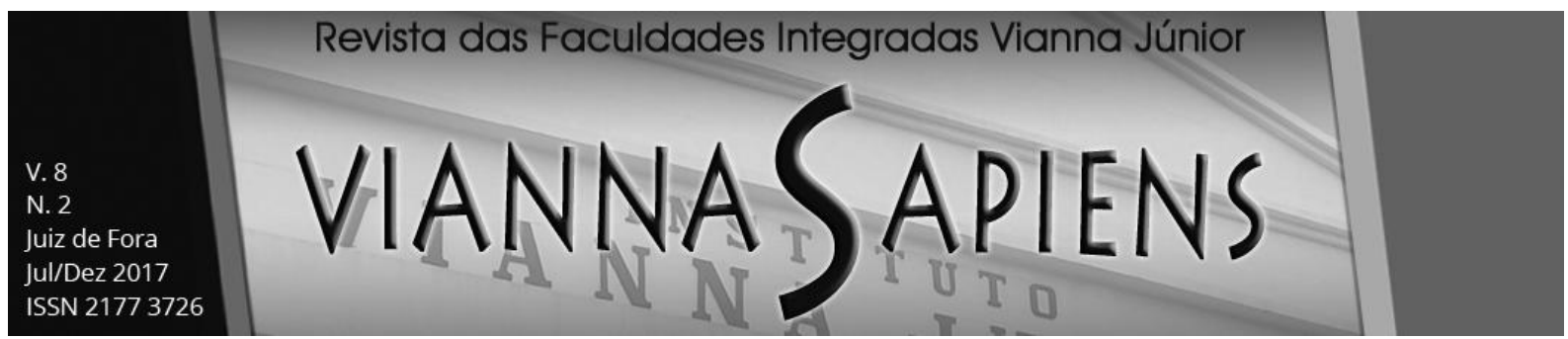

um sinônimo de desenvolvimento social, e passam a ser alguns dos seus indicadores, conjuntamente com o desenvolvimento social (educação, saúde, moradia, alimentação, dentre outros), a desigualdade social e outros elementos. Portanto, atualmente, não temos o desenvolvimento econômico como o direito ao desenvolvimento completo, mas é somente uma parte deste.

Por isso, foi desenvolvido o Índice de Desenvolvimento Humano (IDH), como foi explicado na segunda parte do artigo, para explicitar a situação do desenvolvimento de cada país.Contudo, as três dimensões desse direito (a longevidade e uma vida saudável, o conhecimento e um padrão de vida decente) ainda não são capazes de demonstrar o real cenário desse direito em cada localização, pois os quatro indicadores utilizados (a expectativa de vida da população ao nascer, a quantidade de anos escolares frequentados por adultos com 25 anos ou mais, a expectativa da quantidade de anos escolares para crianças em idade escolar e o coeficiente GINI) são somente uma fração de diversos outros em que uma nação pode ou não progredir, como, por exemplo, o "Índice Nacional de Preços ao Consumidor Amplo" (IPCA) e os índices relacionados à densidade populacional. Dessa forma, o IDH foi uma evolução para a verificação da aplicação do direito ao desenvolvimento nos países, porém ele não engloba todos os segmentos sociais e não consegue demonstrar nitidamente a real situação do direito, por isso é necessáriaa criação de um índice mais completo e com mais indicadores.

Sobre o desenvolvimento interno, o governo de cada nação deve focar em cada região e aplicar políticas diferenciadas, visto que cada área tem suas peculiaridades, carências e suficiências. No caso do Brasil, o IDHMunicipal é um dos índices que demonstra a desigualdade dentre as regiões desse extenso país no quesito territorial. Uma das principais conclusões desse estudo pode ser depreendida dessa parte do estudo, pois não é normal duas regiões tão próximas (como uma favela do Rio de Janeiro e um bairro de classe alta da mesma cidade) com IDH tão distintos, por isso o objetivo principal desse estudo seria demonstrar 


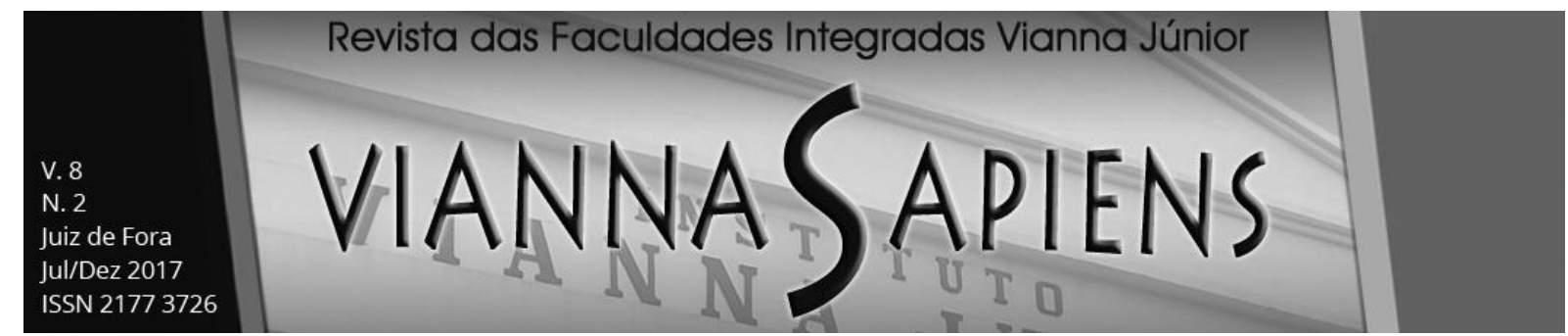

essa distinção e provocar a intervenção dos governantes para amenizar essa situação.

Outra conclusão que se pode depreender do presente estudo é a divisão entre direito ao desenvolvimento da nação e do indivíduo. A terceira parte do artigo estudou o desenvolvimento do indivíduo, que configura na necessidade de cada serhumano ter todos seus direitos concedidos para um desenvolvimento integral. Um exemplo seria a igualdade de oportunidades, porque alguns grupos de pessoas detêm um leque de possibilidades, enquanto outros não possuem nenhuma opção.

Por fim, o estudo desse direito não está findado aqui, ainda há diversos pontos discutíveis e com a necessidade de mudanças. Portanto, permanece o questionamento: "como é possível em um mesmo país termos o IDH da Noruega e da Ruanda?"

\title{
RIGHT TO DEVELOPMENT IN THE FIELDS OF THE DEVELOPMENT OF THE NATION AND DEVELOPMENT OF THE INDIVIDUAL
}

\begin{abstract}
The right to development encompass the application of all the rights to the free development of a human-being personality, therefore, this work analyzed the two dimensions of the right to development, the development of the individual and the nation's development, as well as the application and it's innovations. This research will be theoretical, bibliographical and documentary. In the context of the development of the nation, this right is linked to economic, social and other developments, which is, it encompasses human progress, with all its variables. Still in the development of the nation, the object of this study still works the egalitarian development. About the development of the individual, it consist in the full enjoyment of rights so that each person can progress. The main conclusions of the study were
\end{abstract}




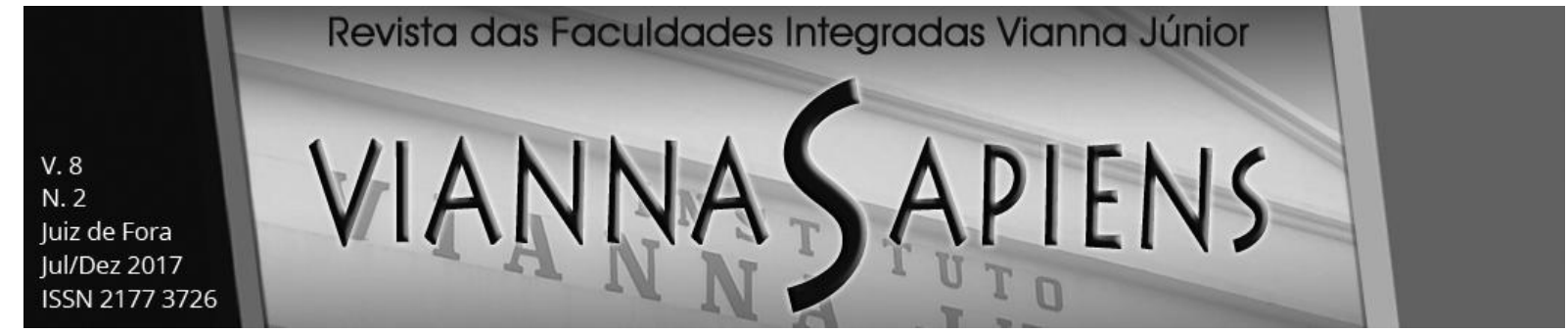

the discrepancy in human development between geographically closely regions, the shift towards the right to development that previously was tied only to economic development, and the need for more accurate human development indicators.

\section{KEY-WORDS: RIGHT TO DEVELOPMENT. NATION.INDIVIDUAL.HDI.HUMAN RIGHTS.}

\section{REFERÊNCIAS}

ANJOS FILHO, Robério Nunes dos. Direito ao desenvolvimento. São Paulo: Saraiva, 2013.

ASSEMBLEIA GERAL DAS NAÇÕES UNIDAS. Declaração sobre o Direito ao Desenvolvimento. 1986. Disponível em: <http://pfdc.pgr.mpf.mp.br/atuacao-econteudos-de-apoio/legislacao/direitos-

humanos/decl_direito_ao_desenvolvimento.pdf>. Acesso em: 24 jun. 2017.

ASSEMBLEIA GERAL DAS NAÇÕES UNIDAS. Resolução número 2.626. 1970. Disponível em:

<http://www.un.org/en/ga/search/view_doc.asp?symbol=A/RES/2626(XXV)>. Acesso em: 24 jun. 2017.

ATLAS DO DESENVOLVIMENTO HUMANO DO BRASIL. O atlas. 2010. Disponível em: <http://www.atlasbrasil.org.br/2013/pt/o_atlas/o_atlas_/>. Acesso em: 03 jul. 2017.

ATLAS DO DESENVOLVIMENTO HUMANO DO BRASIL. Ranking - Todo o Brasil. 2010. Disponível em: <http://www.atlasbrasil.org.br/2013/pt/ranking>. Acesso em: 03 jul. 2017. 


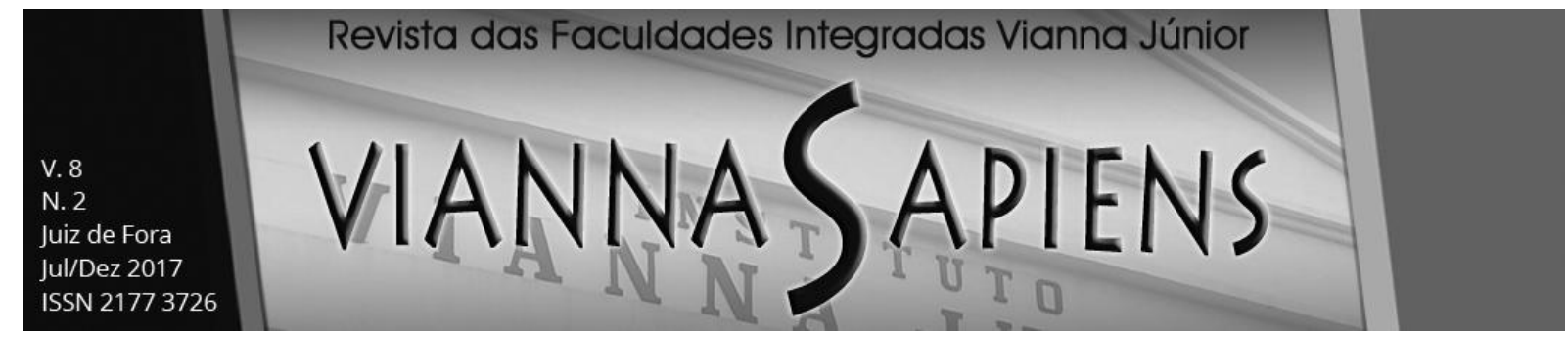

BKA. Police Crime Statistcs. 2015. Disponível em:

$<$ https://www.bka.de/SharedDocs/Downloads/EN/Publications/PoliceCrimeStatistics/ 2015/pks2015_englisch.pdf?_blob=publicationFile\&v=3>. Acesso em: 10 ago.

2017.

BOBBIO, Norberto. A Era dos direitos. Tradução: COUTINHO, Carlos Nelson. Apresentação: LAFER, Celso. Rio de Janeiro: Elsevier, 2004.

BRASIL. Constituição (1988). Constituição da República Federativa do Brasil. Brasília, DF: Senado Federal. Disponível em:

$<$ http://www.planalto.gov.br/ccivil_03/constituicao/constituicao.htm>. Acesso em: 24 jun. 2017.

COMISSÃO INTERAMERICANA DE DIREITOS HUMANOS. Convenção Americana sobre Direitos Humanos. Costa Rica: 1969. Disponível em:

<https://www.cidh.oas.org/basicos/portugues/c.convencao_americana.htm>. Acesso em: 24 jun. 2017.

COMPARATO, Fábio Konder. A afirmação histórica dos direitos humanos. Ed. 10. São Paulo: Saraiva, 2015.

ESPIELL, Héctor Gros. El derecho al desarrollo como un derecho de la persona humana. Revista de Estudios Internacionales, V. 1. N. 1. 1980. Disponível em: $<$ https://www.google.com.br/url?sa=t\&rct=j\&q=\&esrc=s\&source=web\&cd=1\&cad=rja \&uact=8\&ved=0ahUKEwidycqJ5szUAhVOI5AKHT_3Dv4QFggoMAA\&url=https\%3A \%2F\%2Fdialnet.unirioja.es\%2Fdescarga\%2Farticulo\%2F2494813.pdf\&usg=AFQjCN Gjyo_DOk6el1M0CoAtprKkzDxDgQ\&sig2=9gwVt2VI7fHMdv6y6k643A>. Acesso em: 24 jun. 2017.

MAZZUOLI, Valerio de Oliveira. Curso de direitos humanos. 3. ed. rev., atual. e ampl. São Paulo: MÉTODO, 2016.

ODM BRASIL. Agenda de Compromissos dosObjetivos de Desenvolvimento do Milênio. 2013. Disponível em:

<http://www.agendacompromissosodm. planejamento.gov.br/agendaCompromisso/in dicadores/InserirDadosProgramaUC/InserirDadosProgramaUC.do?idlniciativa=1\&nu meroCompromisso=1 >. Acesso em: 09 jul. 2017. 


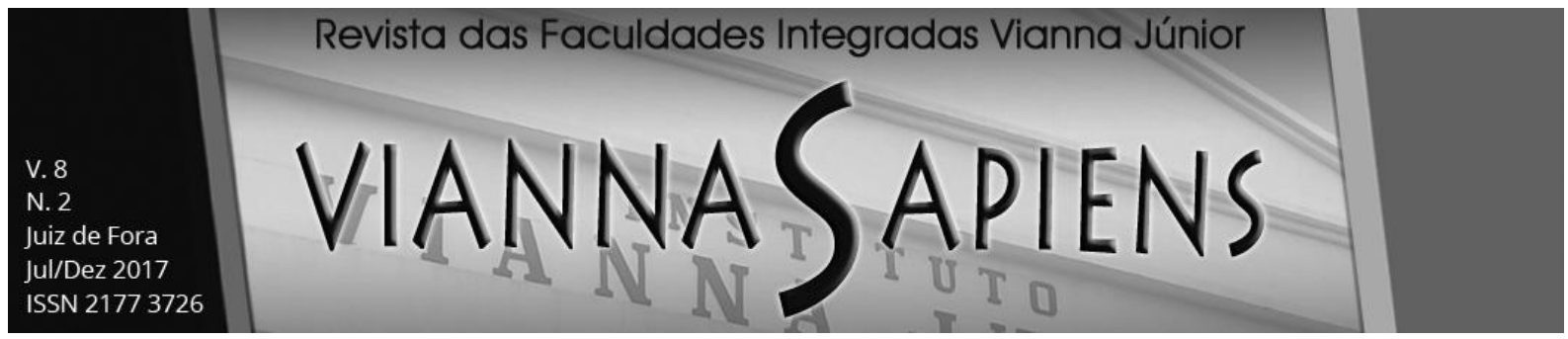

ODM BRASIL. Objetivos de Desenvolvimento do Milênio. 2000. Disponível em: $<$ http://www.odmbrasil.gov.br/os-objetivos-de-desenvolvimento-do-milenio 2000>. Acesso em: 09 jul. 2017.

ONU. Declaração do Milênio. 2000. Disponível em: $<$ https://www.unric.org/html/portuguese/uninfo/DecdoMil.pdf>. Acesso em: 09 jul. 2017.

ORGANIZAÇÃO DAS NAÇÕES UNIDAS. Declaração Universal dos Direitos Humanos. 1948. Disponível em : <http://www.onu.org.br/img/2014/09/DUDH.pdf>. Acesso em: 24 jun. 2017.

PIOVESAN, Flávia. Direitos humanos e o direito constitucional internacional. 16. ed.rev., ampl. e atual. São Paulo: Saraiva, 2016.

PNDU BRASIL. Desenvolvimento Humano e IDH. 2017. Disponível em: <http://www.br.undp.org/content/brazil/pt/home/idh0.html>. Acesso em: 03 jul. 2017.

PNUD BRASIL. Agenda 2030. 2015. Disponível em:

<http://www.agenda2030.org.br>. Acesso em: 10 ago. 2017.

PNUD BRASIL. O que é o IDH. 2017. Disponível em: $<$ http://www.br.undp.org/content/brazil/pt/home/idh0/conceitos/o-que-e-o-idh.html>. Acesso em: 24 jun. 2017.

RICUPERO, Rubens. Eleventh session of the Conference. 2004. Disponível em: $<$ http://unctad.org/en/pages/MeetingsArchive.aspx?meetingid=4289>. Acesso em: 09 jul. 2017.

SEN, Amartya. Desenvolvimento como liberdade. São Paulo: Companhia das letras, 2010.

SENADO FEDERAL. Evolução do IDH do Brasil. 2013. Disponível em: <http://www12.senado.leg.br/emdiscussao/edicoes/pacto-federativo/infograficos-daedicao/info_205_evolucao_idh>. Acessoem: 10 ago. 2017. 


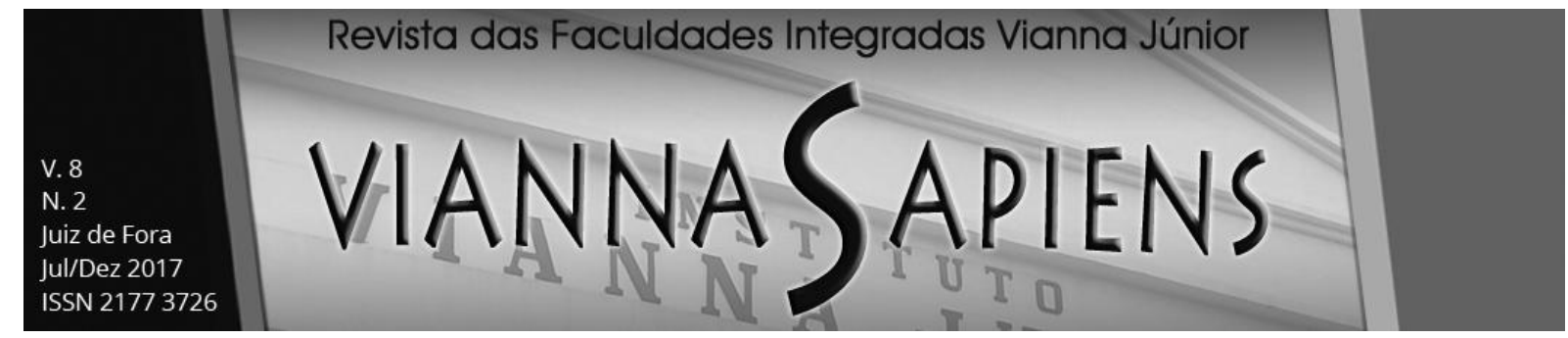

SENGUPTA, Arjun; NEGI, Archna; BASU, Moushumi. Reflections on the right to development. New Delhi: 2005. Disponível em: <

https://books.google.com.br/books?hl=en\&lr=\&id=WsOGAwAAQBAJ\&oi=fnd\&pg=PA 61\&ots=GyKJoE8CJ2\&sig=uOupn14VLj6ZKMEVTogy5M99KWA\#v=onepage\& $q \& f=f$ alse>. Acesso em: 24 jun. 2017.

SINESP. Relatório Consolidado de Ocorrências de homicídios dolosos registrados pela Polícia Civil. 2014. Disponível em:

<https://www.sinesp.gov.br/estatisticas-publicas>. Acesso em: 10 ago. 2017.

UNCTAD. Conferences. 2014. Disponível em:

<http://unctad.org/en/Pages/Meetings/UNCTAD-Conferences.aspx>. Acesso em: 09 jul. 2017.

UNCTAD. From decisions to actions. 2016. Disponível em:

$<$ http://unctad.org/en/PublicationsLibrary/unctad_xivd1_en.pdf>. Acesso em: 09 jul. 2017.

UNITED NATIONS DEVELOPMENT PROGRAMME. About Human Development. 2016. Disponível em: <http://hdr.undp.org/en/humandev>. Acessoem: 03 jul. 2017.

UNITED NATIONS DEVELOPMENT PROGRAMME. Human Development Index (HDI). 2016. Disponível em: <http://hdr.undp.org/en/content/human-developmentindex-hdi>. Acessoem: 03 jul. 2017.

UNITED NATIONS DEVELOPMENT PROGRAMME. Human Development Index and its components. 2015. Disponível em: <http://hdr.undp.org/en/composite/HDl>. Acesso em: 03 jul. 2017.

UNITED NATIONS DEVELOPMENT PROGRAMME. Income Gini coefficient. 2013. Disponível em: <http://hdr.undp.org/en/content/income-gini-coefficient>. Acesso em: 03 jul. 2017. 


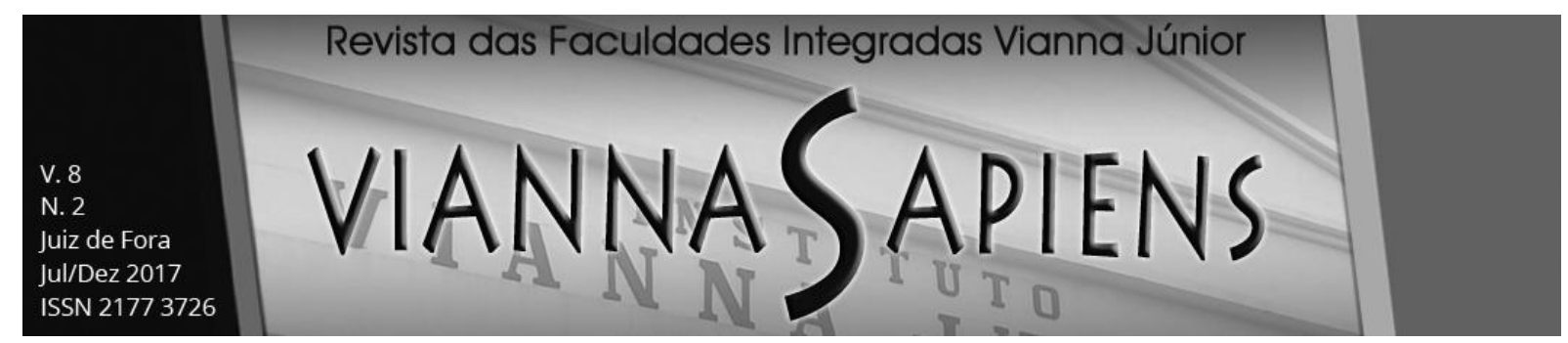

VASCONCELLOS, Marco Antonio Sandoval de; GARCIA, Manuel Enriquez.

Fundamentos de economia. Ed. 4. São Paulo: Saraiva, 2008.

WOLFFENBÜTTEL, Andréa. O que é? - Índice de Gini. Desafios do desenvolvimento. 4.ed. A. 1. Brasília: 2004. Disponível em:

$<$ http://www.ipea.gov.br/desafios/index.php?option=com_content\&id=2048:catid=28\& Itemid=23>. Acesso em: 24 jun. 2017.

WORLD BANK. Gross domestic product 2016. 2016. Disponível em:

<http://databank.worldbank.org/data/download/GDP.pdf>. Acesso em: 03 jul. 2017. 